Journal of Sustainable Agricultural Sciences
http://jsas.journals.ekb.eg/

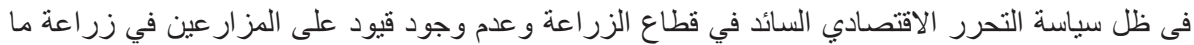

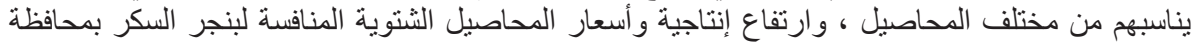

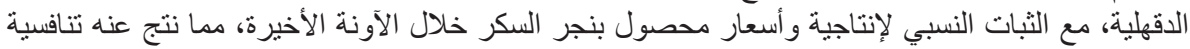

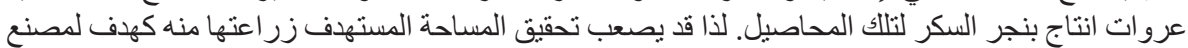

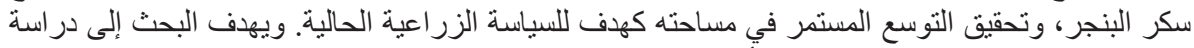

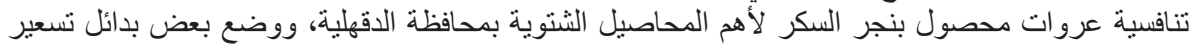

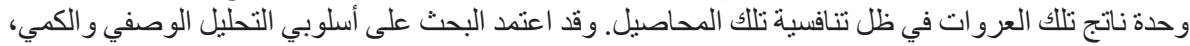

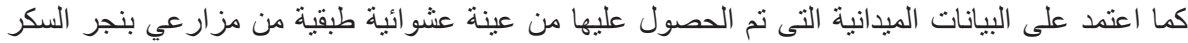

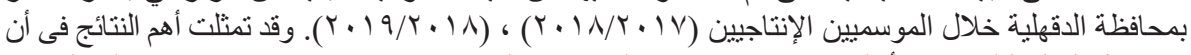

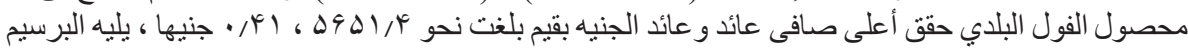

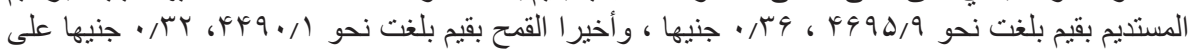

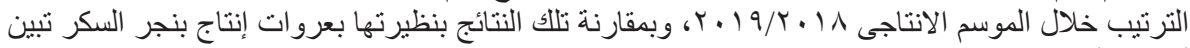

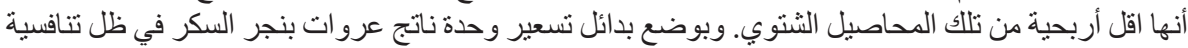

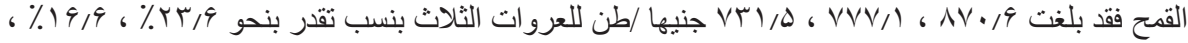

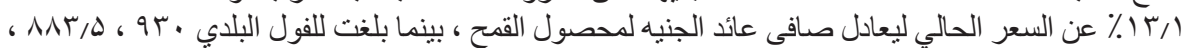

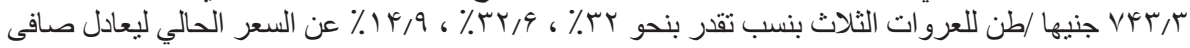

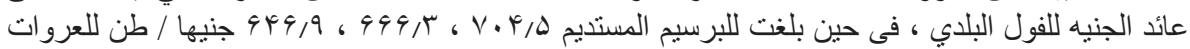

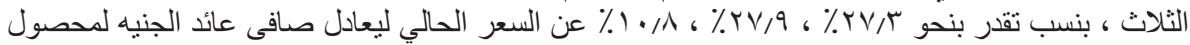

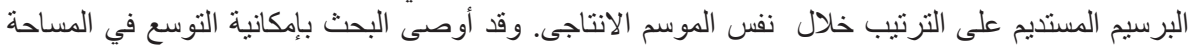

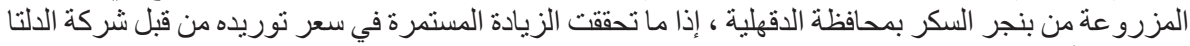
اللسكر ، الأمر الذي يعادل صافى عائده مع الدحاصيل الثنتوية المنافسة له محل الدر استة.

الكلمات المفتاحية : تنافية ، العروات الإنتاجية ، محصول بنجر السكر ، المحاصيل الثتوية ، التكاليف الانتالجية ، صافى العائد الفانى ، عائد الجنيه، ، الكفاءة الاقتصادية.

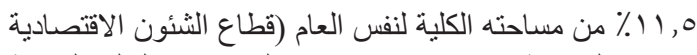

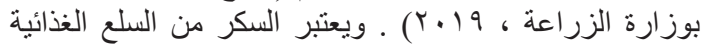

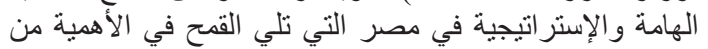

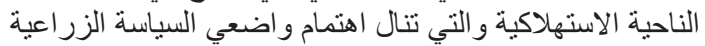

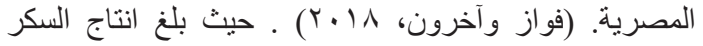

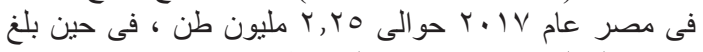

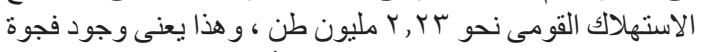

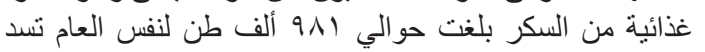

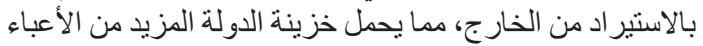

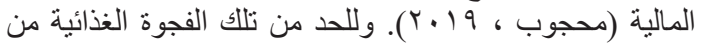

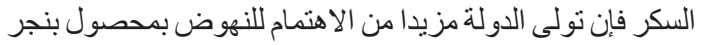

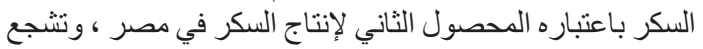

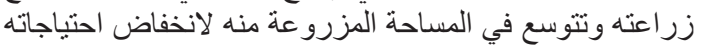

المقدمة

يعد محصول بنجر السكر من المحاصيل الشتوية التي تجود

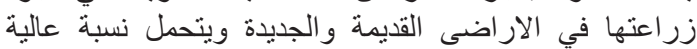

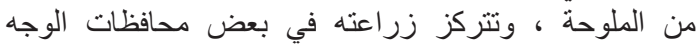

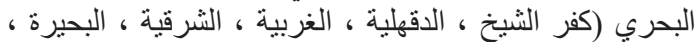

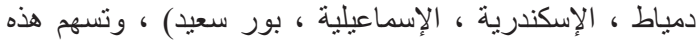

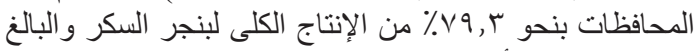

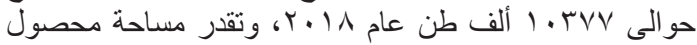

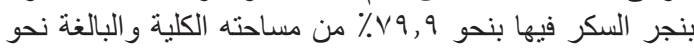

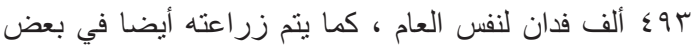

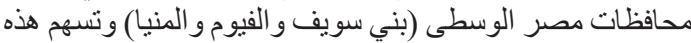

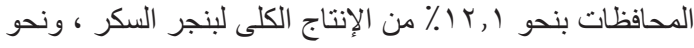




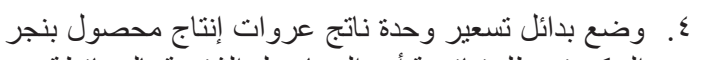
السكر في ظل تنافسية أهم المحاصيل الشتوية بالج بالمحافظة .

\section{الطربقة البحثبة و مصادر البيانات}

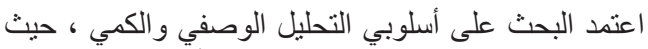

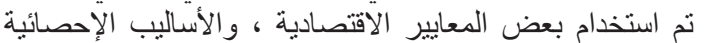

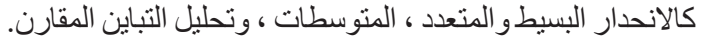

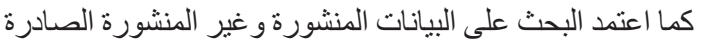

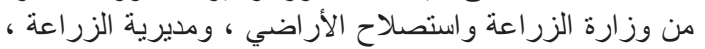

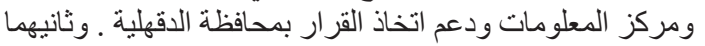

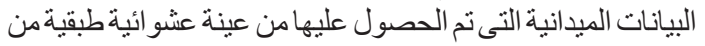
مزارعي بنجر السكر بالمحافظة . وقد تم تصميم استمارة استبيان

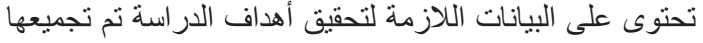

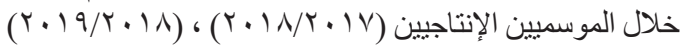

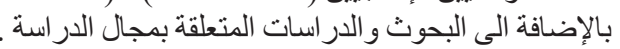

عينة الدر اسة الميدانية

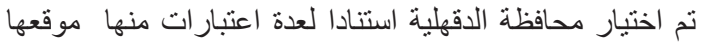

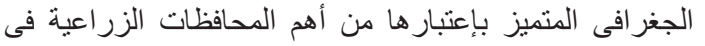

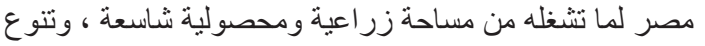

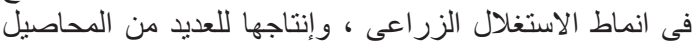

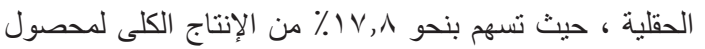

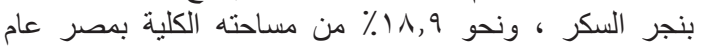

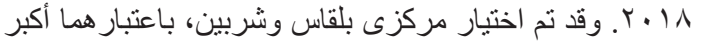

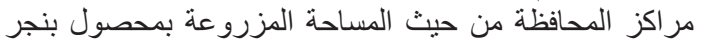

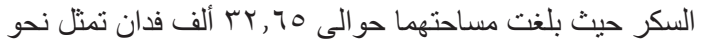

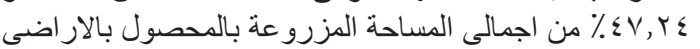

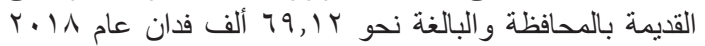

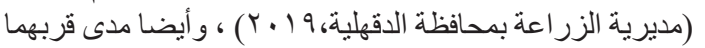

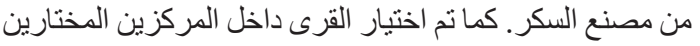

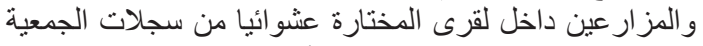

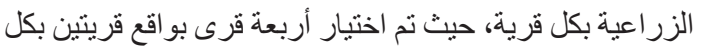

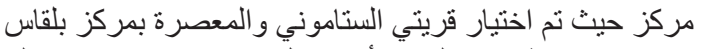

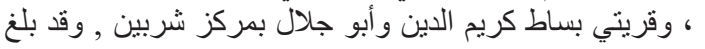

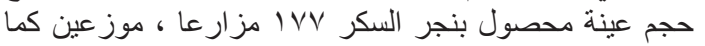
بلى : 97 حائز ا بمركز بلقاس موز عة عة على على قريتي الستاموني

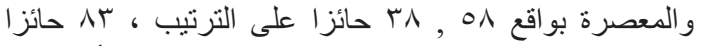

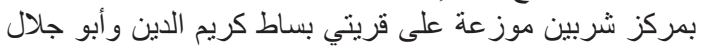

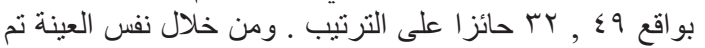

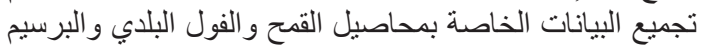

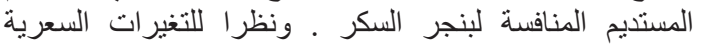

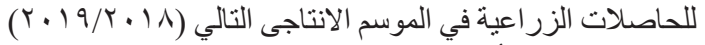

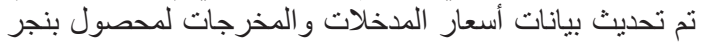

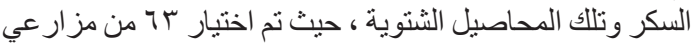

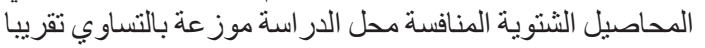

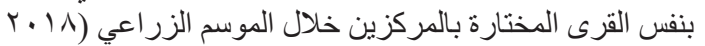

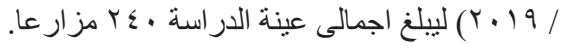

النتائج البحثية ومناقثشاتها

أولا: مؤشرات إنتاج محصول بنجر السكر بمحافظة الدقهلية

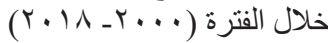

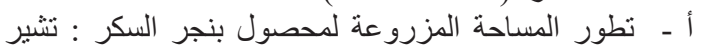

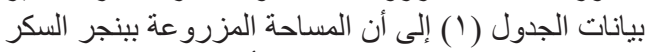

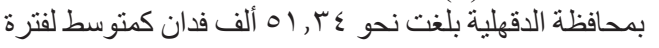

من مياه الري وخاصة في ظل الظروف الر اهنة لترشيد استخدام

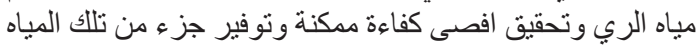

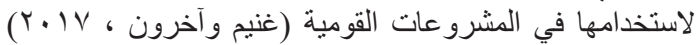

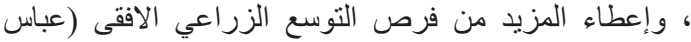

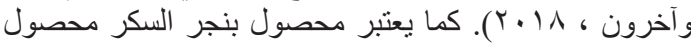

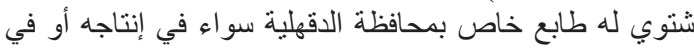

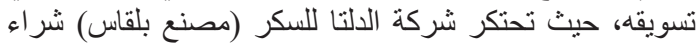

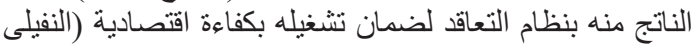

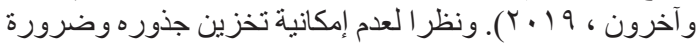

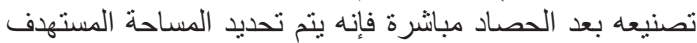

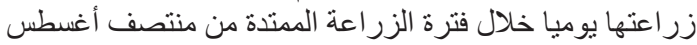

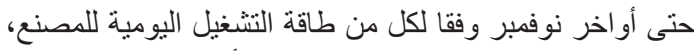

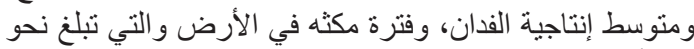

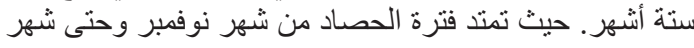

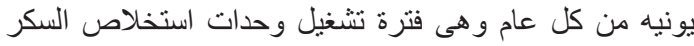

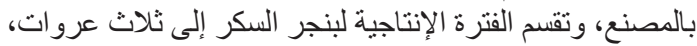

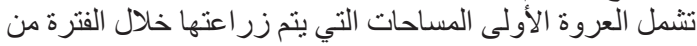

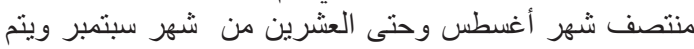

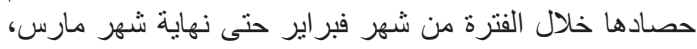

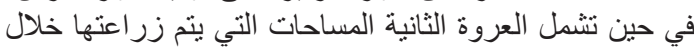

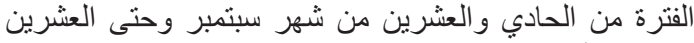

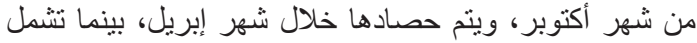

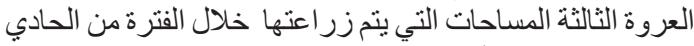

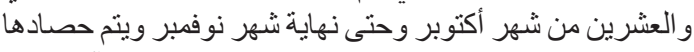

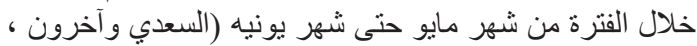

. ( Y . . O

مشكلة الدر استة

في ظل سياسة التحرر الاقتصادي السائد في قطاع الزر اعة ،

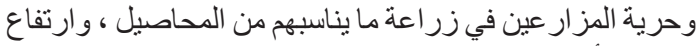

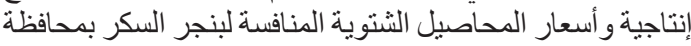

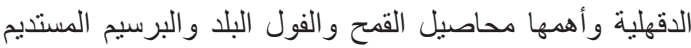

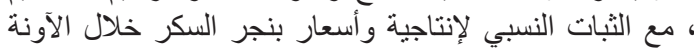

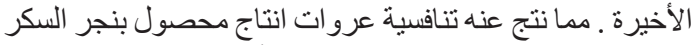

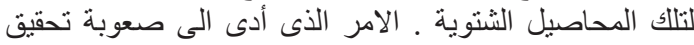

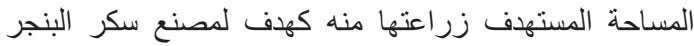
من ناحية، وتحقيق التوسع المستمر في مساحته كهدف لـاعنه للسياسة

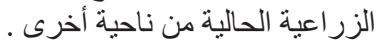

أهداف الدراسة

يهدف البحث بصفة رئيسية إلى دراسة وتحليل تنافسية

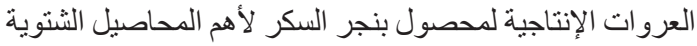

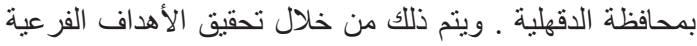
التالية :

ا. دراسة اقتصاديات عروات إنتاج محصول بنجر السكر الثلاث بمحافظة الدقهلية خلاتل المات الموسميين الانتاجيين $(r+19 / r+11) \cdot(r+11 / r+1 V)$

r. تقدير المؤشرات الاقتصادية لاستخدام الموارد المزرعية

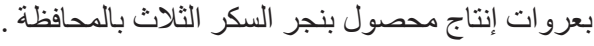

r. دراسة اقتصاديات إنتاج أهم المحاصيل الثتوية المنافسة

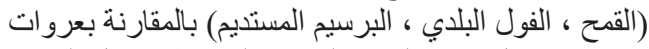

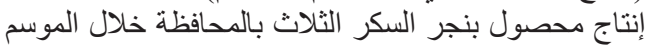

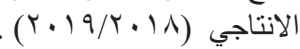

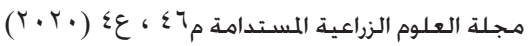




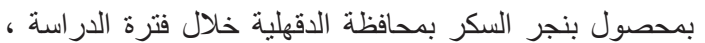

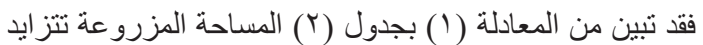

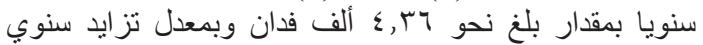

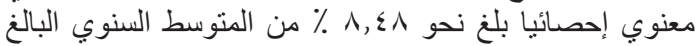

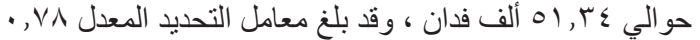

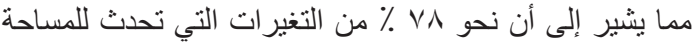

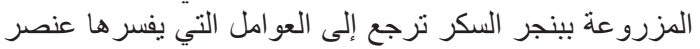

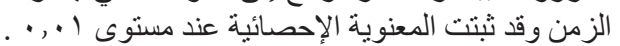

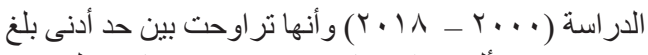

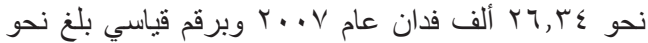

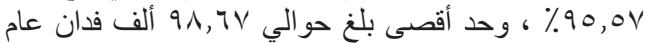

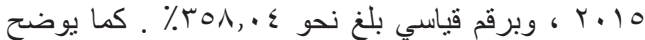

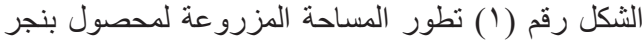
السكر بمحافظة الدقهلية خلال نفس الفترة .

وبتقدير معادلة الاتجاه الزمني العام لتطور المساحة المزروعة

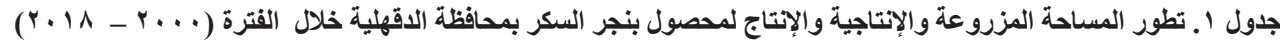

\begin{tabular}{|c|c|c|c|c|c|c|}
\hline القياسبي & الإنتاجية الفدانية & الرقم القياسي & ألانتاج الكلى فدان & الرقم القياسي & ألمساحة المزروعة & البيان \\
\hline $1 \ldots, \ldots$ & IV,rT & $1 \ldots, \ldots$ & $\leqslant \vee \leqslant, \wedge 1$ & $1 \ldots, \ldots$ & $r V, 0 T$ & $r \ldots / 1999$ \\
\hline $117, r 1$ & $r \cdot, \cdot \varepsilon$ & $|r|, \wedge 0$ & $0 \vee \wedge, 00$ & $1 \cdot \varepsilon, V T$ & $Y \wedge, \wedge \curlyvee$ & $r \ldots 1 / r_{\ldots} .$. \\
\hline$\| V, r \leq$ & $r \cdot, r$. & $|r|, \varepsilon \lambda$ & OVฯ, Vq & I.r,Tr & $r \wedge, 00$ & $r \ldots r / r \ldots l$ \\
\hline $11 \wedge, \leqslant 7$ & $r \cdot, \Sigma l$ & $1 \leqslant r, 7 r$ & $T V V, Y \leq$ & $M r_{\bullet}, \varepsilon r$ & Tr, 19 & $r \ldots r / r \ldots r$ \\
\hline $117, r v$ & $r \cdot, .0$ & $|1 r, r|$ & ors,.r & $q \vee, r \wedge$ & rד,N & $r \ldots \varepsilon / r \ldots r$ \\
\hline $117, r v$ & $r \cdot, .0$ & $11 \mathrm{~V}, \cdot \varepsilon$ & $000, \mathrm{~V}$. & $1 \cdots, 01$ & $r V, V Y$ & $r \ldots o / r \ldots \varepsilon$ \\
\hline$\| \wedge, Y \wedge$ & $r \cdot, r \Lambda$ & $T r \varepsilon, r$ & זr,דזד & $\| T, r V$ & MI, Y & $r \ldots r / r \ldots o$ \\
\hline$\| V, Y \leq$ & $r \cdot, r$. & $\| r, \cdot \varepsilon$ & orl, 9v & $90,0 \mathrm{~V}$ & $r T, r \leq$ & $r \ldots v / r \ldots r$ \\
\hline דוג, ודו & YY,VY & $197,7$. & דצ & $1 \leq 9,19$ & $\leqslant 1,11$ & $r \cdots \wedge / r_{\cdots} \cdot v$ \\
\hline $90, \wedge r$ & 17,01 & Mr,Y & orr,. & 118,10 & Tr,YA & $r \ldots q / r \ldots \wedge$ \\
\hline $1 \cdot 7, \vee \vee 9$ & $1 \wedge, \varepsilon$. & $\| r, \varepsilon \lambda$ & or,$\wedge$, & $1.7, Y 4$ & r৭, r^ & $r \cdot 1 \cdot / r \ldots q$ \\
\hline $\mid 17, \pi 1$ & YI., 9 & rmo,rq & $111 \mathrm{~V}, 1 \wedge$ & 194,19 & Or,97 & $r+11 / r+1$. \\
\hline$\wedge \varepsilon, \vee \varepsilon$ & $1 \leqslant, 7$. & 179,91 & A. 7, Vo & r..,or & $00, Y_{7}$ & $r+1 r / r+11$ \\
\hline $117, \cdot 1$ & $r \cdot, \ldots$ & $r \leqslant Y, V Y$ & $17 r V, r \varepsilon$ & r9o, ro & דו, & $r \cdot 1 r / r \cdot 1 r$ \\
\hline $1.1,0 \mathrm{~V}$ & $I V, O$. & rrr,q. & lorv, 9. & MiN, 9 . & $\wedge \vee, \wedge \Lambda$ & $r+1 \leqslant / r+1 r$ \\
\hline $1 \cdot \leq, \varepsilon 1$ & $1 v, 99$ & $r \leqslant V, 0 T$ & $170 ., 17$ & & $91, \mathrm{~V}$ & $r \cdot 10 / r+1 \varepsilon$ \\
\hline $9 \vee, 7 \wedge$ & Iד,Ar & $r \leq q, V r$ & $177 ., 00$ & rON, $\cdot \varepsilon$ & $9 \wedge, 7 \vee$ & $r .1 T / r+10$ \\
\hline $1 \cdot 7, V r$ & $1 \wedge, \varepsilon$. & rTV,. T & $17 \ldots$, ^ & T10,TV & $\wedge 7,99$ & $r .1 v / r+17$ \\
\hline$M r \cdot, V q$ & $r, r, Y)$ & $\{1 \cdot, 0 \mathrm{~V}$ & $19 \leqslant 9, \leqslant r$ & $r \backslash \Lambda, \varepsilon r$ & $\wedge \vee, V^{\prime}$ & $r \cdot 1 N / r \cdot 1 V$ \\
\hline- & $19,1 \varepsilon$ & - & $9 \vee \varepsilon, 99$ & - & $01, r \varepsilon$ & المتوسط \\
\hline
\end{tabular}

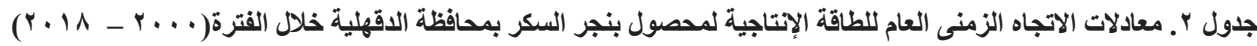

\begin{tabular}{|c|c|c|c|c|c|c|}
\hline معدل التغير & $F$ & $\left(\mathbf{R}^{r}\right)$ & المتوسط & معادلة الاتجاه الزمني العام & المتغير التابع & r \\
\hline$\wedge, \varepsilon \wedge$ & $\cdots$ & $\cdot, \vee \wedge$ & $01, r \leq$ & 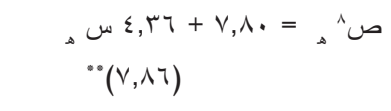 & المساحة المزروعة & 1 \\
\hline$\wedge, 1 \wedge$ & "or, ₹ & $\cdot, \mathrm{V}$ & $9 V \varepsilon, 9$ & 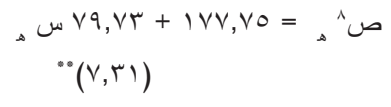 & الإنتاج الكلى طن) & $r$ \\
\hline$\cdot, \mathrm{V} 4$ & "r, & $\cdot, 11$ & $19,1 \leq$ & 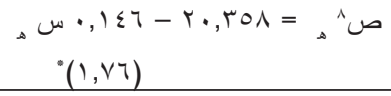 & $\begin{array}{c}\text { الإنتاجية الفدانية } \\
\text { (طن/فدان) }\end{array}$ & $r$ \\
\hline
\end{tabular}

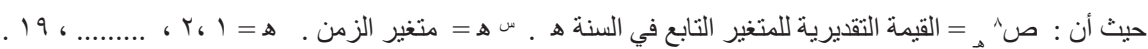

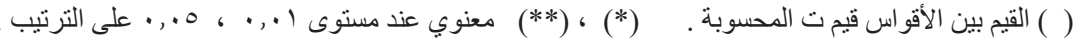

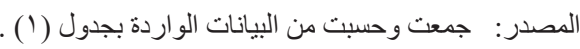

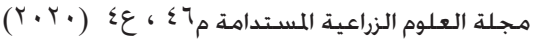




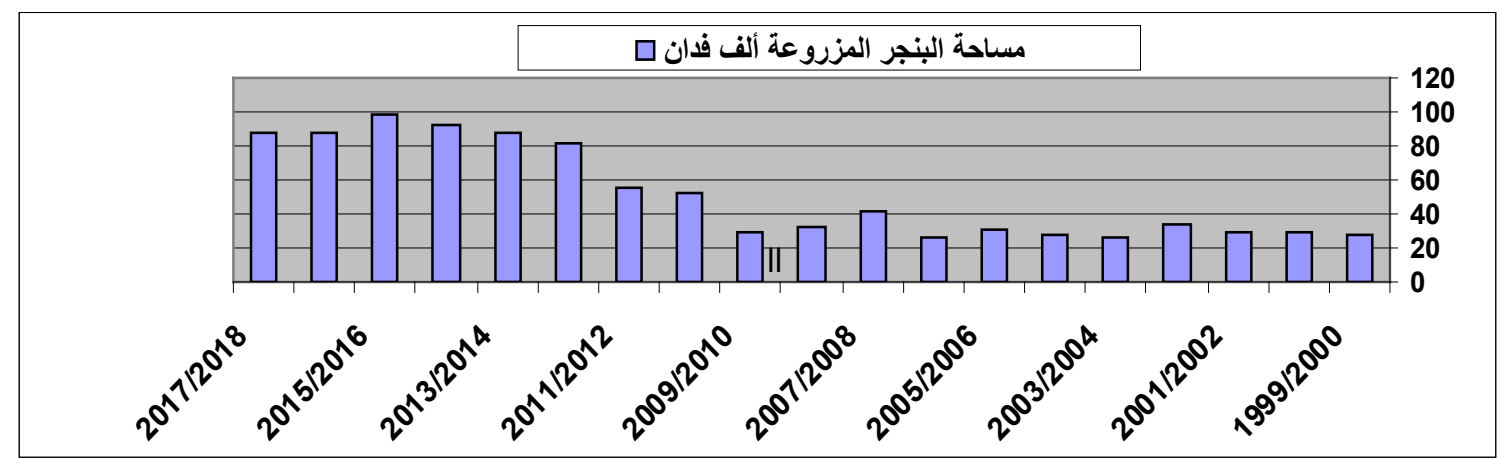

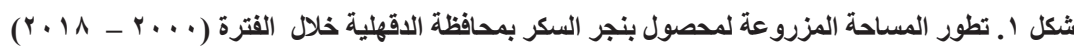

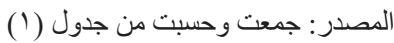

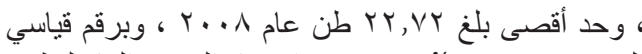

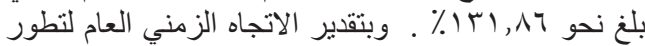

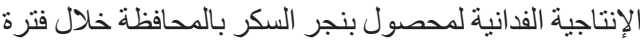

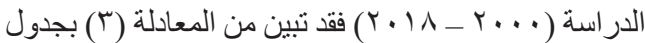

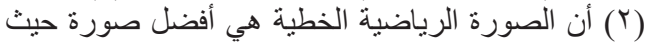

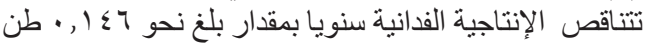

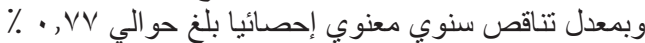

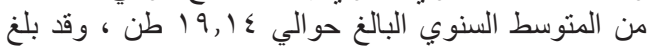

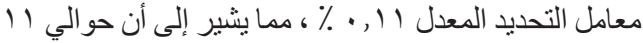

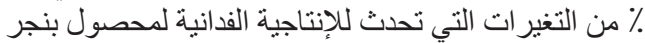

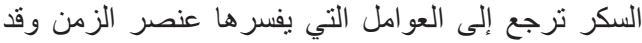

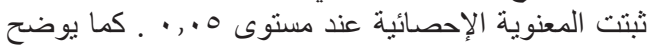
شكل رقم (T) تطور الإنتاجية الفدانية لمحصول الإنة بنجر السكر بمحافظة الدقهلية خلال نفس الفترة

ثانيا: الملامح الاقتصادية لعروات إنتاج محصول بنجر السكر بـرك بمركز ى بلقاس وشربين بعينة الدراسة:

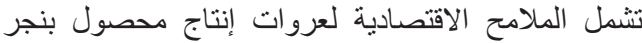

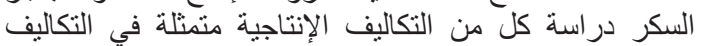

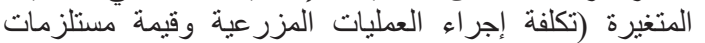

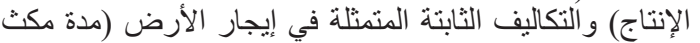

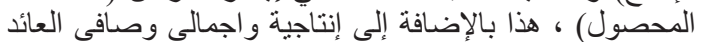

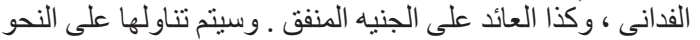

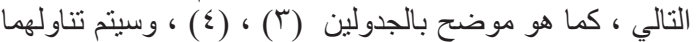
وذللك على النحو التالي : مورج

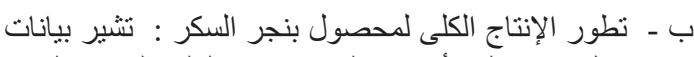

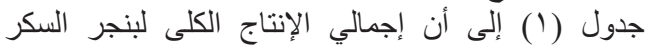
بالمحافظة بلغت نحو

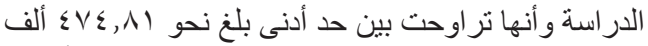

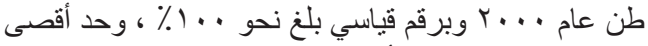

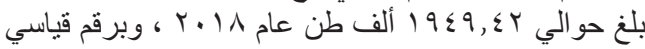

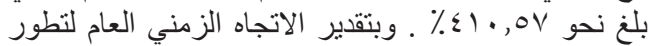

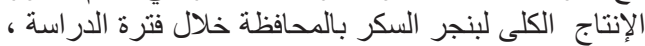

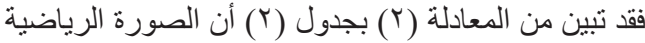

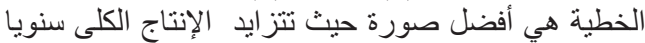

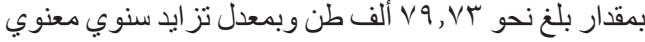

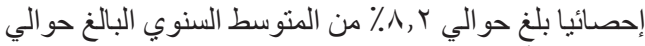

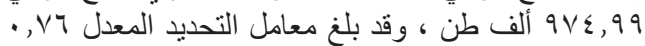

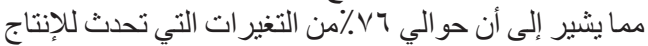

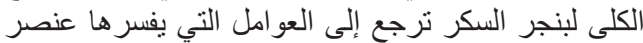

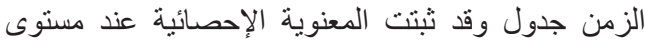

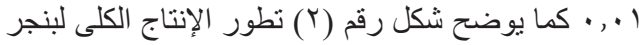

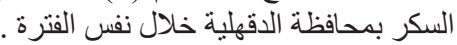

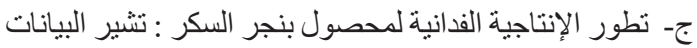

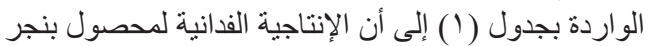

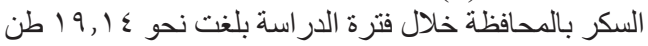

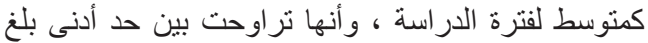

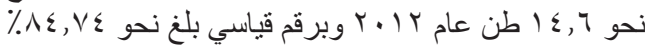

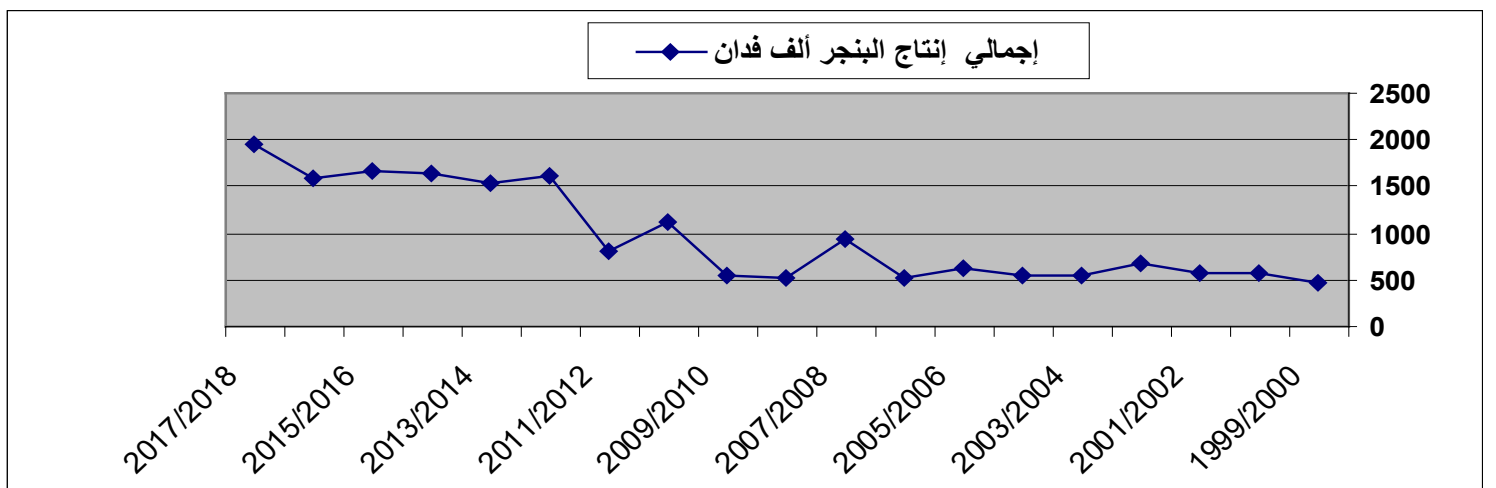

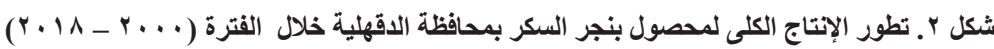
المصدر : جمعت وحسبت من الجدول رقم (1) . (1) .

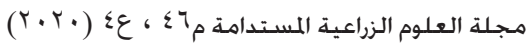




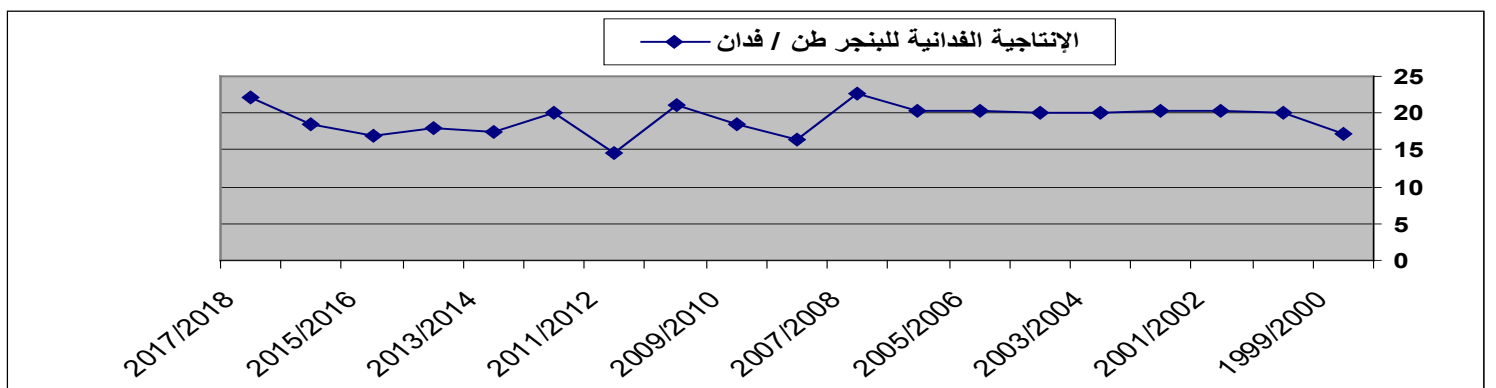

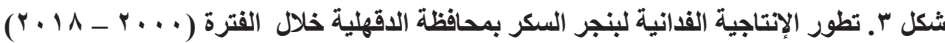

المصدر : جمعت وحسبت من الجدول رقم (1) )

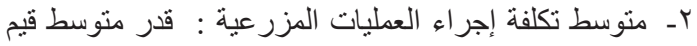

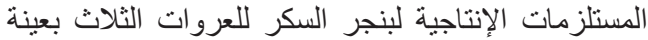

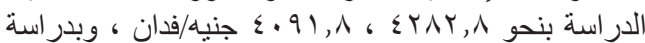

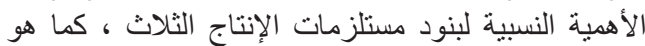

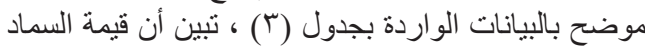

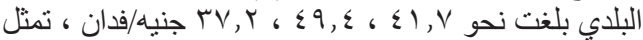

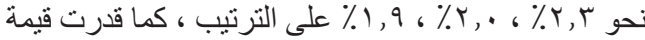

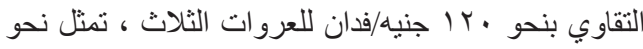

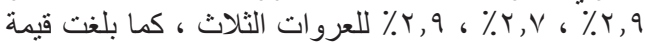

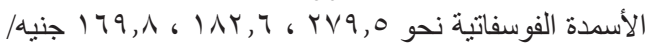

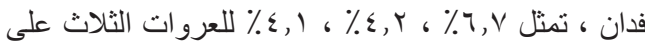

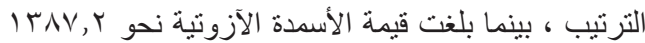

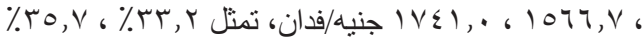

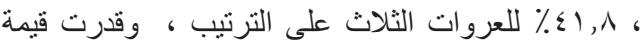

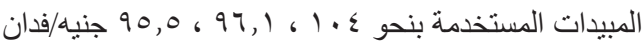

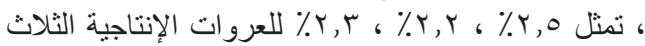

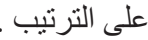

1 - ـ متوسط تكلفة إجر اء العمليات المزر عية : قدر منوسط تكلفة إجر اء العمليات المزر عية لبنجر السكر للعروات التهات الثثلاث بعينة

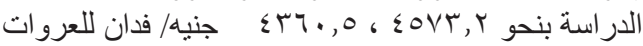

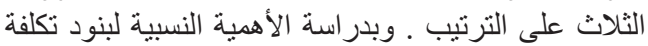

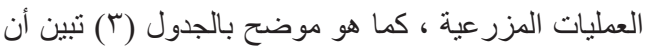

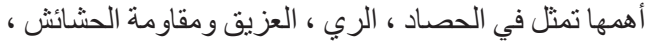

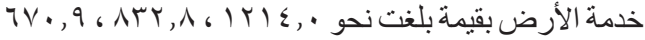

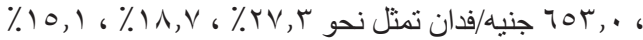

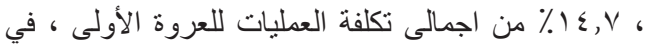

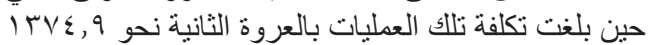

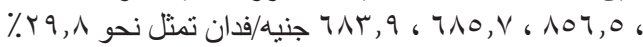

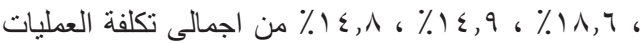

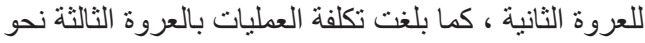

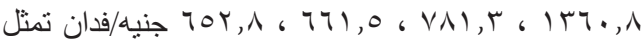

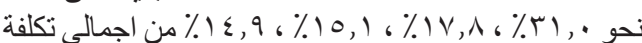

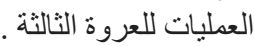
(جنيه/فدان)

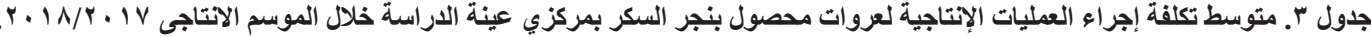

\begin{tabular}{|c|c|c|c|c|c|c|c|c|c|c|c|}
\hline جملة العمليات & مصاريف & الحصاد * & مقاومة & الري & الكقل ونثر & الحشائش العريق & والترقيع & الزراعة & خدمة الأرض & نقل ونثر البماد & البيان \\
\hline \multicolumn{12}{|c|}{ العروة الأولى } \\
\hline$\varepsilon O V T, Y$ & $1 \cdots, r$ & Irro,. & rrq,q & $\Lambda \vee 0,0$ & ITr,. & $71 ., 0$ & rrq, દ & rYo, I & $\pi \cdot, \varepsilon$ & $110, r$ & بلقاس \\
\hline 政, O & 94,7 & $11 r r, 1$ & $1, r, r$ & $\Lambda \cdot 1, r$ & ITr, & עדודי & $r T \cdot, r$ & $r q \cdot, r$ & $\backslash \wedge \varepsilon, Y$ & $\mid \vee \Upsilon, \varepsilon$ & شربين \\
\hline$\varepsilon \leqslant 0 r, 1$ & १७,० & $|r| \leq, \cdot$ & $\mid V \varepsilon, \varepsilon$ & הז, & $1 \leq \varepsilon, 9$ & $7 v \cdot, q$ & rol, $\varepsilon$ & & ror,. & $10 ., 0$ & العينة \\
\hline $1 \ldots$ & $r, r$ & $r v, r$ & $r, q$ & $\mid \wedge, V$ & $r, r$ & 10,1 & 0,7 & 0,9 & $1 \varepsilon, V$ & $r, \varepsilon$ & $\%$ \\
\hline \multicolumn{12}{|c|}{ العروة الثانية } \\
\hline$\leqslant 079,$. & $99, r$ & r, & rTO,A & AVฯ, & $1 \leq q, v$ & $\neg \wedge \vee, \wedge$ & Y01,T & $r \leq r, 0$ & TrT,V & $\leqslant r, \varepsilon$ & بلقاس \\
\hline$\Sigma \Psi \vee T, \cdot$ & $1 \cdot 0, \varepsilon$ & $1 \% q \leq, \leq$ & $1 \leq \varepsilon, 0$ & $\Lambda \Gamma \cdot, \Lambda$ & $17 \cdot, V$ & 794,9 & $r \leq \cdot, T$ & rAr,o & Vדr,q & $07, r$ & شربين \\
\hline$\leq 7,9, r$ & $1 \cdot 1,9$ & $1 T V \varepsilon, q$ & 197,7 & 107,0 & $10 \leqslant, \varepsilon$ & $7 \wedge 0, V$ & $r \leq \nearrow, \wedge$ & $r 7 \cdot, 1$ & マイץ,q & $\{\wedge, \varepsilon$ & العينة \\
\hline $1 \ldots$ & $r, r$ & $r q, \wedge$ & $\varepsilon, r$ & $1 \wedge, 7$ & r, & $1 \leq, 9$ & $0, \varepsilon$ & 0,7 & $1 \leq, \wedge$ & 1,1 & $\%$ \\
\hline \multicolumn{12}{|c|}{ العروة الثالثة } \\
\hline$\varepsilon \leqslant 00, V$ & 1,1 & IrAY,I & $1 \leqslant r, r$ & $\Lambda \cdot r, T$ & $171, \varepsilon$ & ס,זדו & $r \leq \cdot, \wedge$ & $r \wedge 0, T$ & $10 \cdot, 1$ & $\leq \varepsilon, 7$ & بلقاس \\
\hline$\leqslant r \leqslant 1, \wedge$ & 97,0 & $\mid r \leq r, 1$ & 110,1 & VTY,T & 101,9 & $7 \leq r, 0$ & rro,A & $r \vee 0, T$ & $T V \cdot, \Lambda$ & $\varepsilon \cdot, r$ & شربين \\
\hline$\leqslant r 90,$. & $\wedge q, r$ & גז., & IYA,O & VAI,r & $17 ., 1$ & & rrA, I & $r \wedge \cdot, r$ & TOY,A & $\varepsilon r, r$ & العينة \\
\hline $1 \ldots$ & $r,$. & M.,. & $r, q$ & $\mathrm{IV}, \mathrm{A}$ & $r, \tau$ & 10,1 & $0, \varepsilon$ & $7, \varepsilon$ & $1 \varepsilon, 9$ & $1, \cdot$ & $\%$ \\
\hline
\end{tabular}

" تشنمل على عمليات التقليع ، التنظيف ، الترحيل ، التعبئة ، النقل .

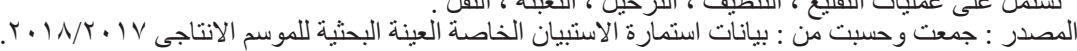

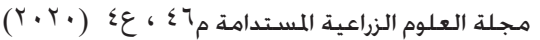




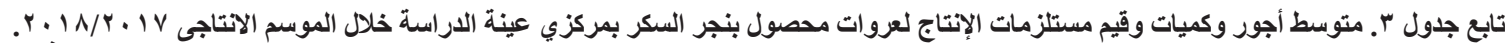
(جنيه/فدان)

\begin{tabular}{|c|c|c|c|c|c|c|c|c|c|c|c|}
\hline \multirow{2}{*}{ الجمالى قيمة } & \multirow{2}{*}{ قالآلي والبشري العمل } & \multirow{2}{*}{ قيمة } & \multicolumn{2}{|c|}{ السماد الآزوتى } & \multicolumn{2}{|c|}{ سوبر فوسفات } & \multicolumn{2}{|c|}{ التقاوي } & \multicolumn{2}{|c|}{ السماد البلدي } & \multirow{2}{*}{ البيان } \\
\hline & & & قيمة & وحدة & قيمة & وحدة & قيمة & كيلو & قيمة & $r^{5}$ & \\
\hline \multicolumn{12}{|c|}{ العروة الأولى } \\
\hline$\varepsilon r \wedge r, \wedge$ & $r q . V, q$ & $1 \cdot 7, V$ & $\mid r \leq \wedge, q$ & $\mid r \cdot, 1$ & r & 11,1 & $r$. & $\varepsilon$ & $7 \varepsilon$, & $r, r$ & بلقاس \\
\hline$\varepsilon .91, \wedge$ & $198 \cdot, 9$ & I.r. & $1 \leqslant \wedge \wedge, \varepsilon$ & $1 \leqslant 1,1$ & rᄉ०,r & $\Gamma, \wedge$ & $r$ & $\varepsilon$ & $r 0, r$ & $1, v$ & شربين \\
\hline$\varepsilon I V T, r$ & $r Y \leq \cdot, 9$ & $1 \cdot \varepsilon$, & $I K \wedge V, r$ & Irr, & rvq,० & $r r, 1$ & ir. & $\varepsilon$ & $\varepsilon 1, v$ & $r, r$ & العينة \\
\hline $1 \ldots$ & or, & $r, 0$ & 促 & - & $T, V$ & - & $r, q$ & - & $1, \cdot$ & - & $\%$ \\
\hline \multicolumn{12}{|c|}{ العروة الثانية } \\
\hline$\varepsilon r \leqslant 0, r$ & TrOT,Y & ᄉr., & $1798, r$ & $1 r_{0,0}$ & $1 \leqslant \Lambda, 7$ & 11,9 & 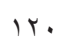 & $\varepsilon$ & $\leq r, \wedge$ & $1, \wedge$ & بلقاس \\
\hline$\varepsilon \leqslant r \leqslant, T$ & rort,A & $11 r, 0$ & וrqr,o & 177,1 & rYA, & $r r, 1$ & $k$. & $\varepsilon$ & $07, \wedge$ & $r, r$ & شربين \\
\hline$\varepsilon r \wedge r, r$ & 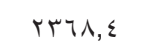 & 97,1 & $1074, \mathrm{~V}$ & $1 \leqslant r, q$ & IAr,T & $17, r$ & $i r$ & $\varepsilon$ & $\varepsilon 9, \varepsilon$ & $r, \cdot$ & العينة \\
\hline $1 \ldots$ & $0 \leqslant,$. & $r, r$ & $r_{0, V}$ & - & $\varepsilon, r$ & - & $r, v$ & - & 1,1 & - & $\%$ \\
\hline \multicolumn{12}{|c|}{ العروة الثالثة } \\
\hline$\varepsilon r r \cdot, V$ & $\backslash \wedge q \vee, \wedge$ & $1 \cdot 1, \varepsilon$ & $1 \wedge \wedge 7,9$ & וAr, & IVT,Y & $10, r$ & 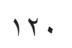 & $\varepsilon$ & ऍへ, 乞 & 1,9 & بلقاس \\
\hline$\varepsilon 1.9,0$ & $r \cdot \wedge \varepsilon, V$ & 91,1 & ITाז,r & TIT, & $17 \varepsilon, 1$ & $1 \Sigma, r$ & Ir. & $\varepsilon$ & r,ד & $1, \wedge$ & شربين \\
\hline$\varepsilon|7|, \varepsilon$ & 1998,0 & 90,9 & $|v \leqslant|,$. & IVT,O & $179, \wedge$ & $1 \leqslant, 7$ & 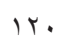 & $\varepsilon$ & $r V, r$ & 1,9 & العينة \\
\hline $1 \ldots$ & $\varepsilon \Lambda$, & $r, r$ & $\varepsilon 1, \wedge$ & _ & $\varepsilon, 1$ & _- & $r, q$ & _ &., 9 & _ & $\%$ \\
\hline
\end{tabular}

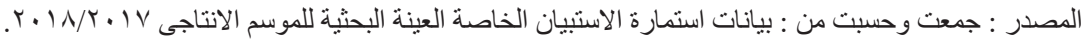

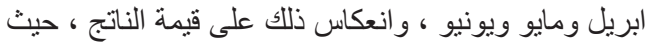

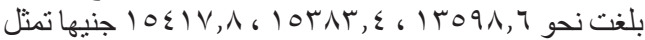

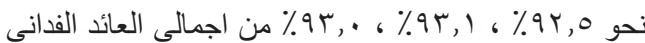
البالغ نحو

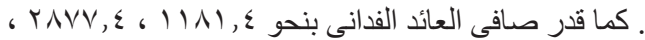

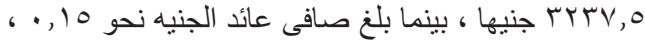

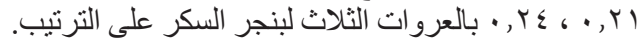

ومما سبق يتضح انه على الرغم من ارتفاع التكاليف الإنتاجية

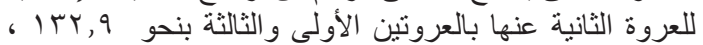

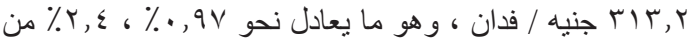

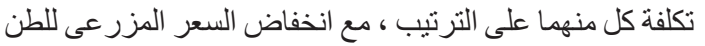

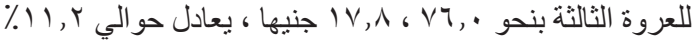

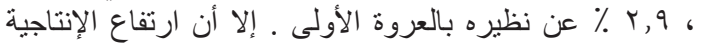

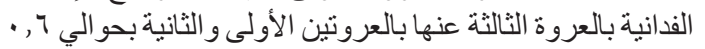

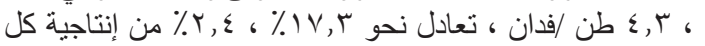

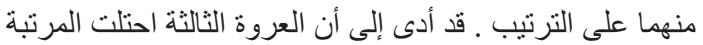

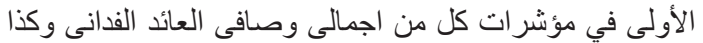

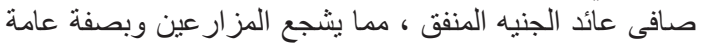

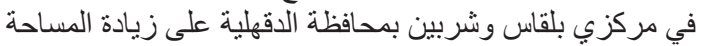

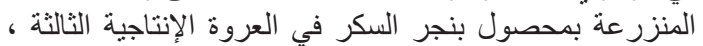

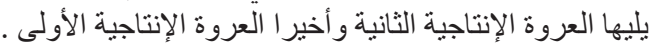

ثالثا: كفاءة استخدام الموارد المزرعية بعروات إنتاج محصول

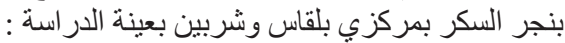

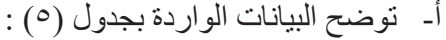

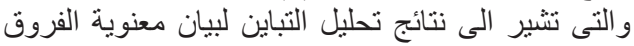

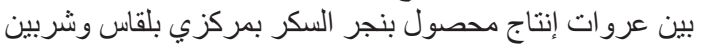

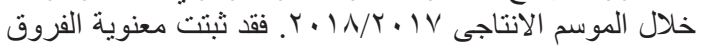

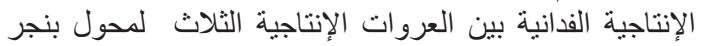

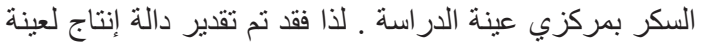

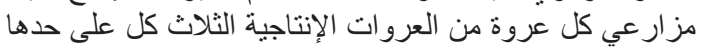

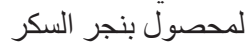

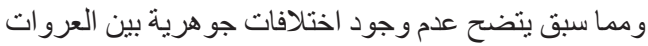

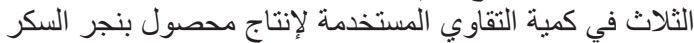

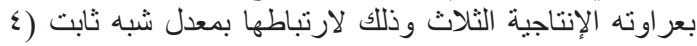

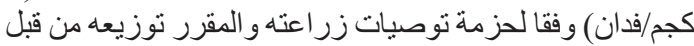

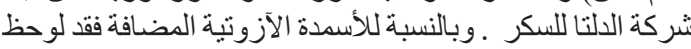

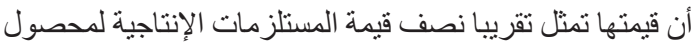

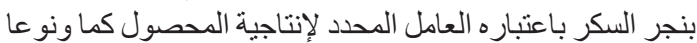

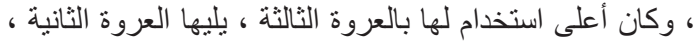

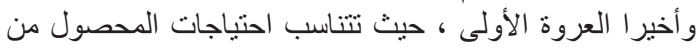

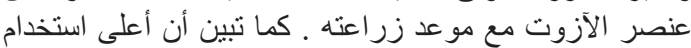

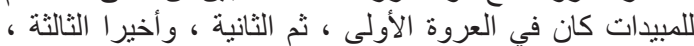

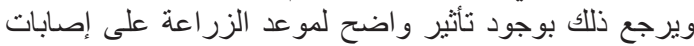

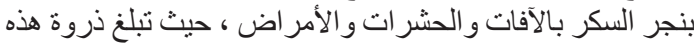

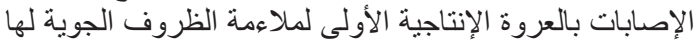

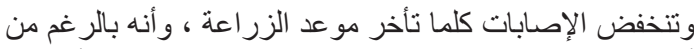

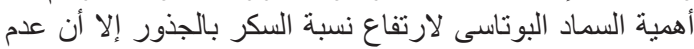

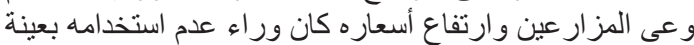

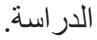

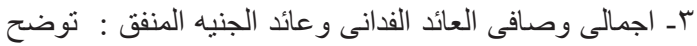

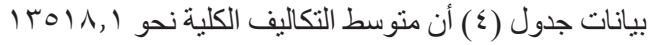

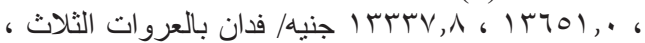

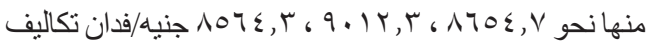

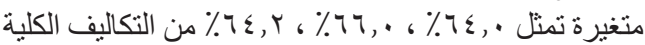

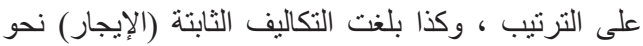
ع

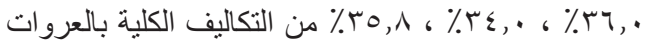

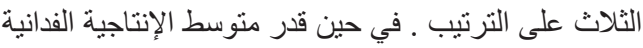

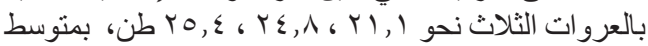

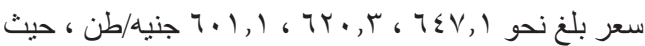

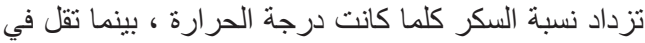

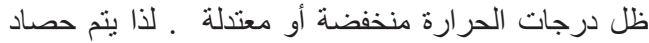

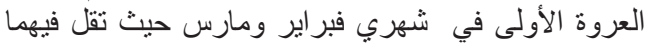

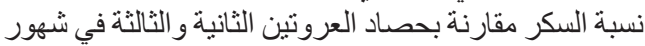

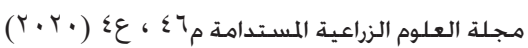




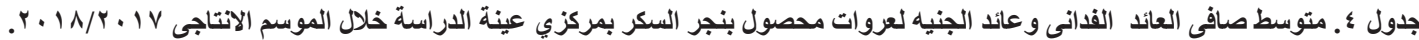
(جنية/فدان)

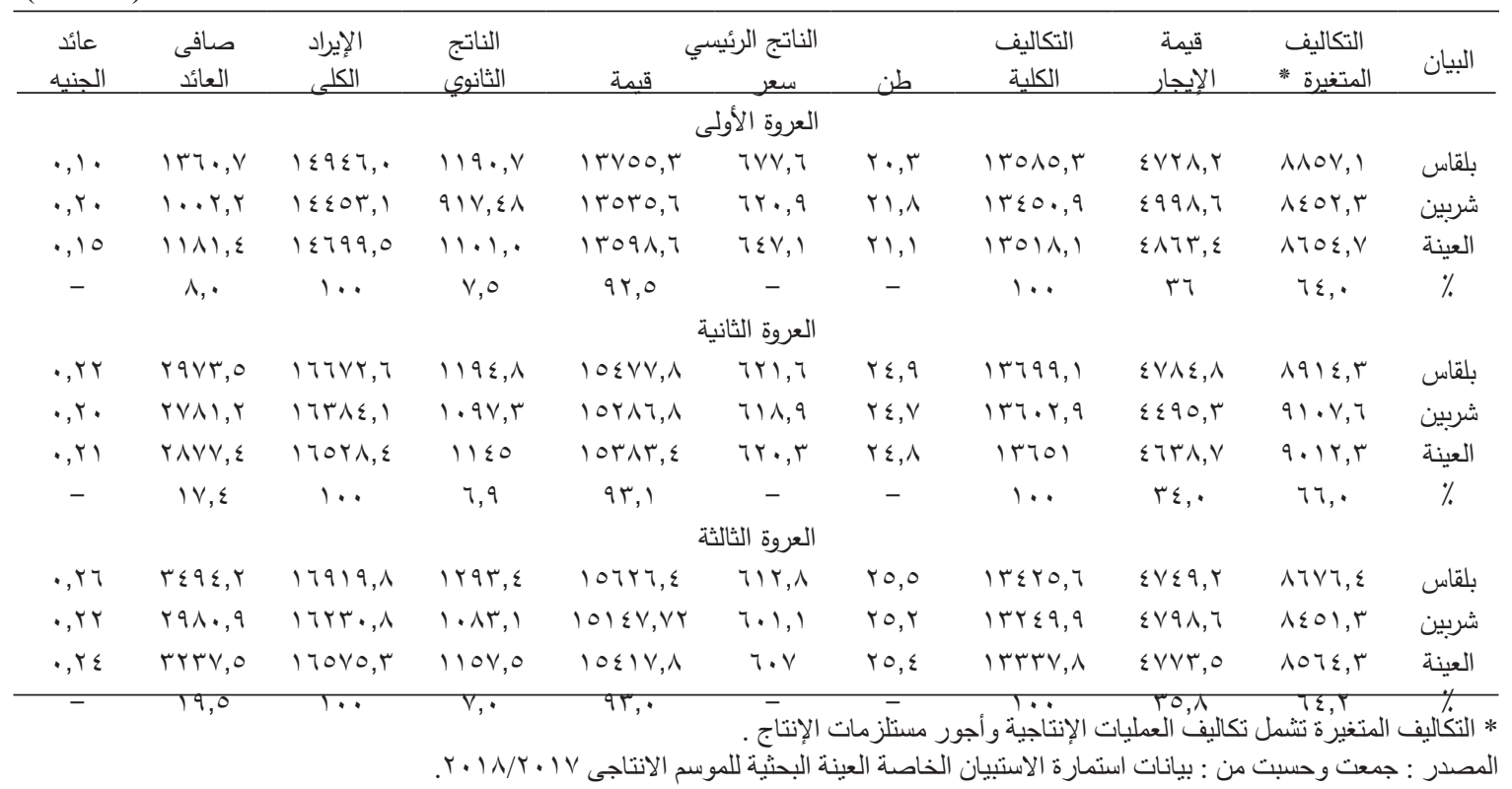

جدول ه. نتائج تحليل التباين المقارن للفروق بين الإتتاجية الفدانية لعروات محصول بنجر السكر بمركزي بلقاس وشربين بعينة الدراسة خلال الموسم

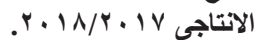

\begin{tabular}{|c|c|c|c|c|c|}
\hline (ف) المحسوبة & متوسط المربعات & مجموع المربعات & درجات الحربة & مصدر الاختلاف & المركز \\
\hline "I T,VT & $r \wedge \Sigma r$ & 0710 & r & بين العروات & \multirow{4}{*}{ بلقاس } \\
\hline *r, r r & TVT & $r \cdot \wedge V \wedge$ & M & داخل العروات & \\
\hline- & Trt & Irی.A & Tr & الخطاً العشوائي & \\
\hline- & - & $\varepsilon \cdot r V r$ & 90 & المجموع & \\
\hline rr, ו" & $r \varepsilon \mid r$ & $\varepsilon \wedge r \wedge$ & r & بين العروات & \multirow{4}{*}{ شربين } \\
\hline$\cdot 1, V r$ & דצדא & $901 \mathrm{~V}$ & Tr & داخل العروات & \\
\hline- & ritr & $11 \cdot V V$ & or & الخطأ العشوائي & \\
\hline- & - & rosin & $\wedge$. & المجموع & \\
\hline
\end{tabular}

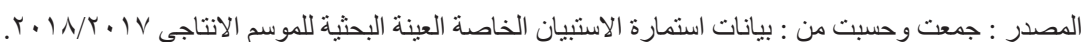

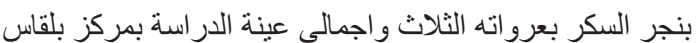

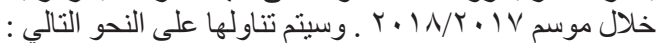

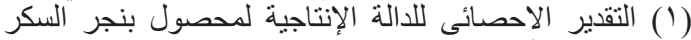

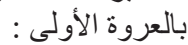

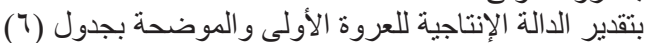

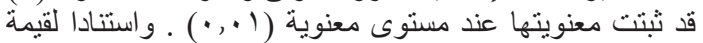

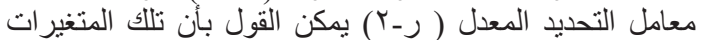

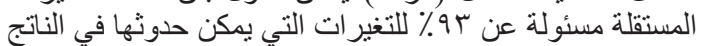

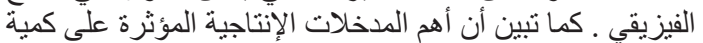

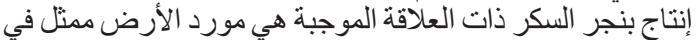

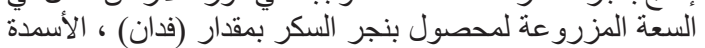

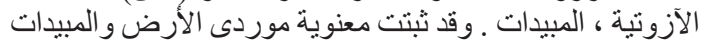

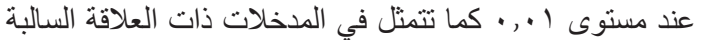

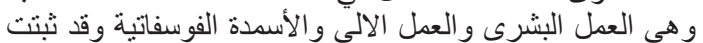

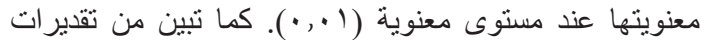

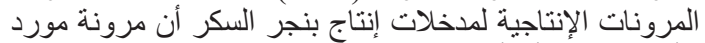

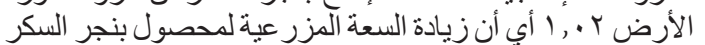

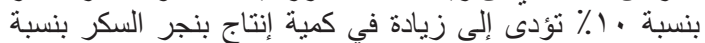

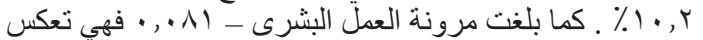

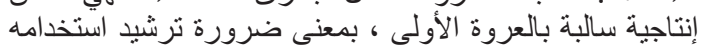

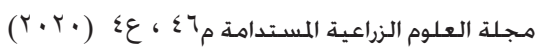

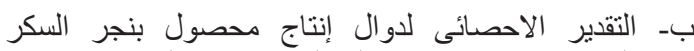

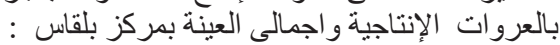

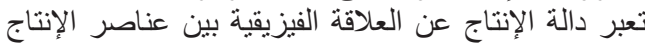
التي تستخدمها الوحدة الإنتاجية وبين الناتجاتية النهائي لهذه الوحدة الإنياجة

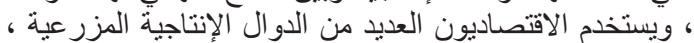

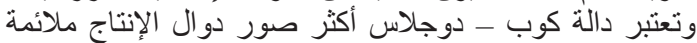

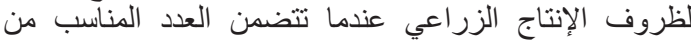

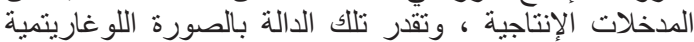

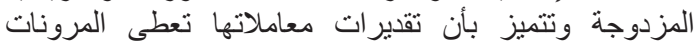

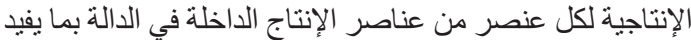

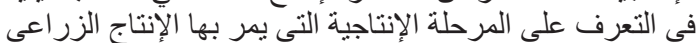

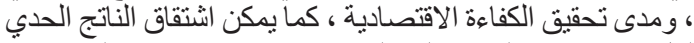

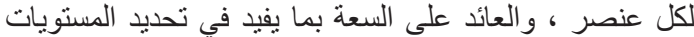

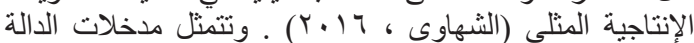

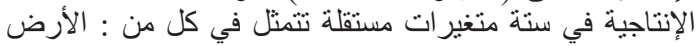

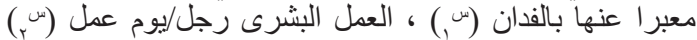

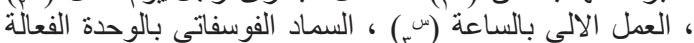

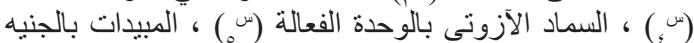

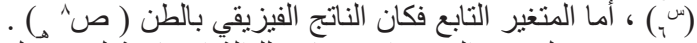

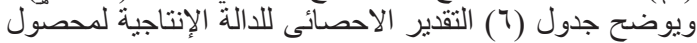


أهم المدخلات الإنتاجية المؤثرة على كمية إنتاج بنجر السكر ذات

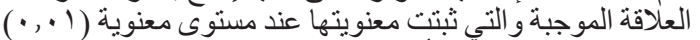

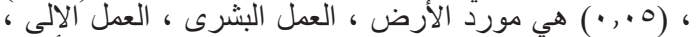

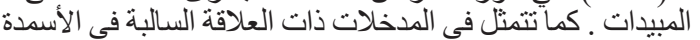

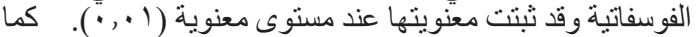

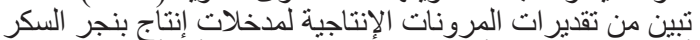

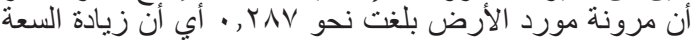

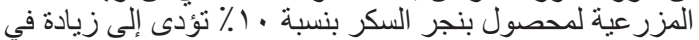

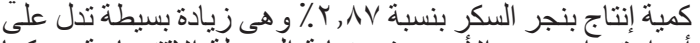

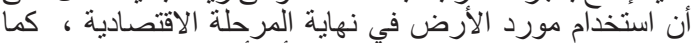

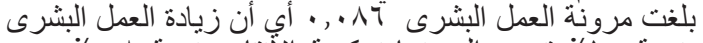

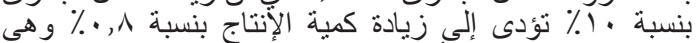

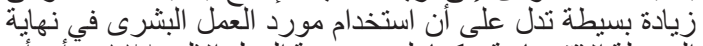

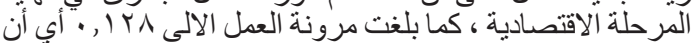

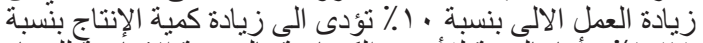

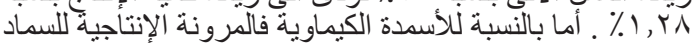

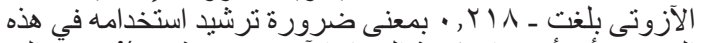

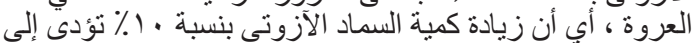

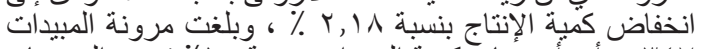

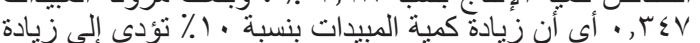

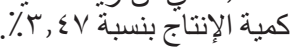

أما بالنسبة للمرونة الإنتاجية الإجمالية للعروة الثانية بمركز

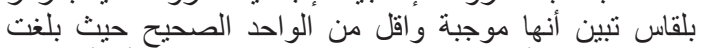

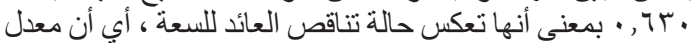

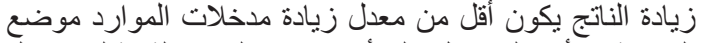

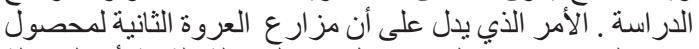

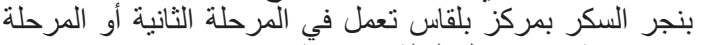

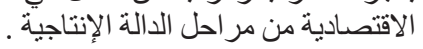

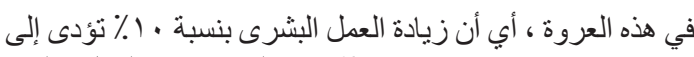

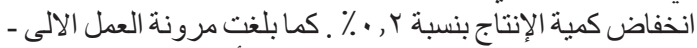

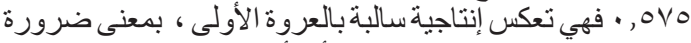

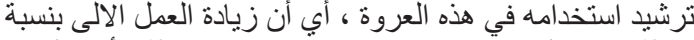

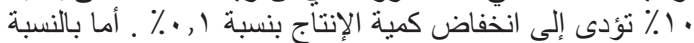

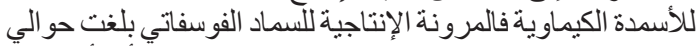

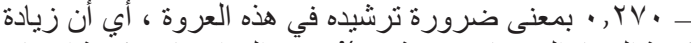

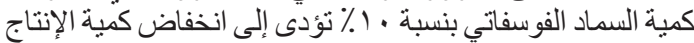

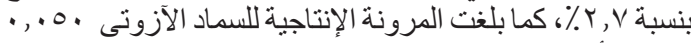

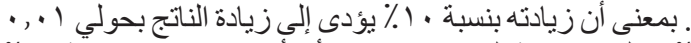

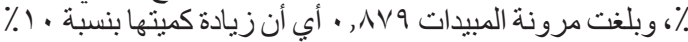

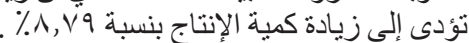

أما المرونة الإنتاجية الإجمالية للعروة الأولى بمركز بلقاس المباس

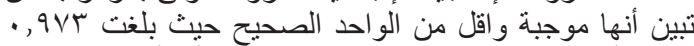

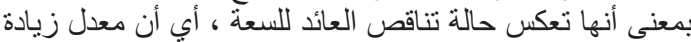

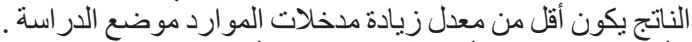

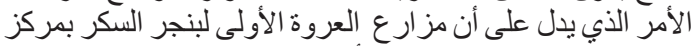

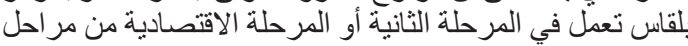

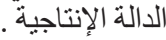

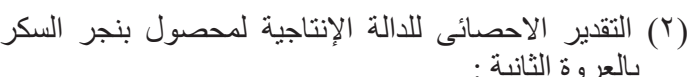
بتقدير الدالة الإنتاجية للعروة الثانية و الموضحة بالجدول رقم

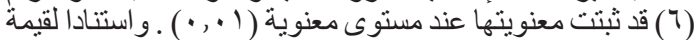

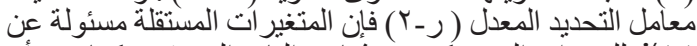
ء^٪ للتغير أت التي يمكن حدوثها في الناتج الفيزيقي ـ كما تبين أن

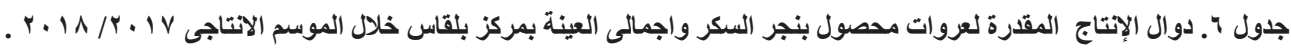

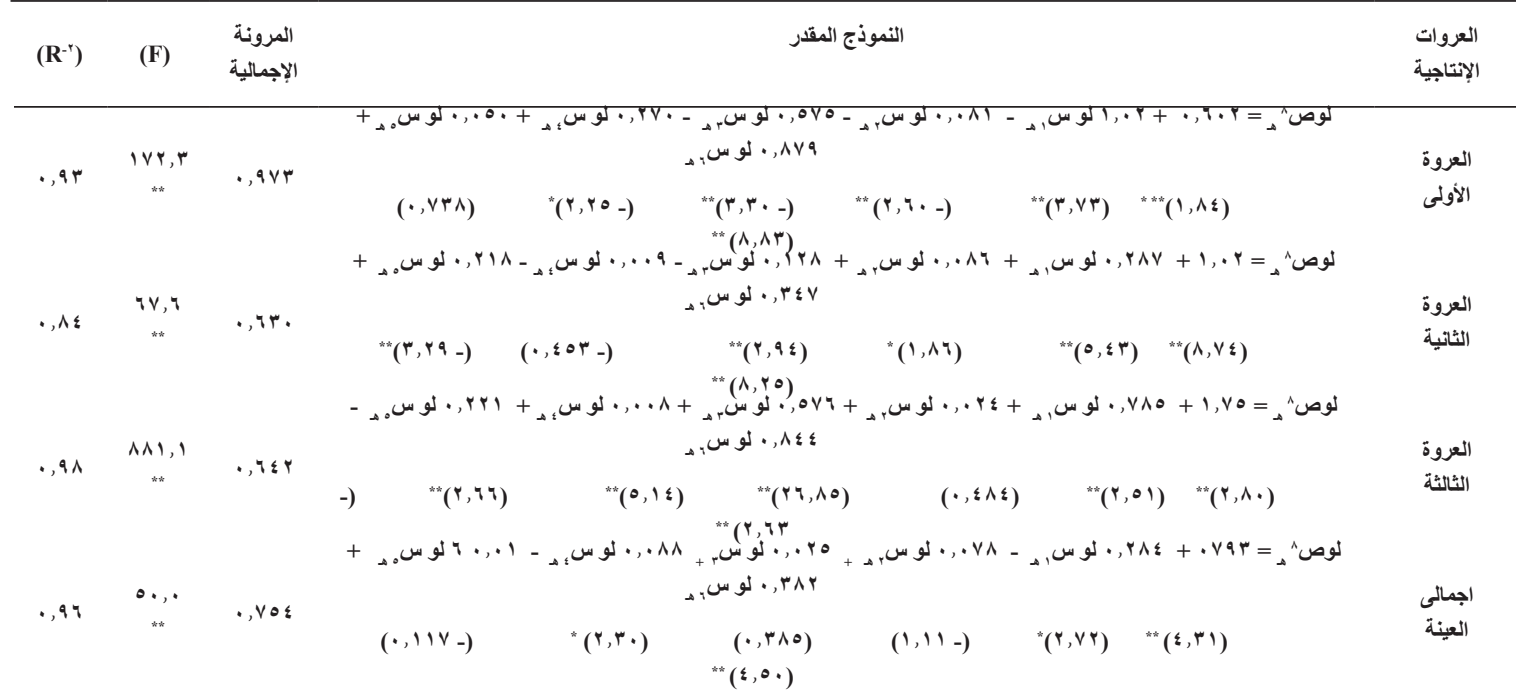

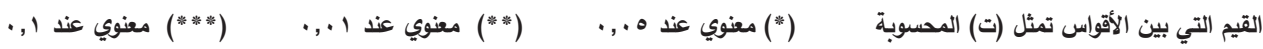

$$
\begin{aligned}
& \text { حيث أن : } \\
& \text { لو ص^ه : لوغاريتم القيمة التقديرية لإنتاج محصول بنجر السكر بالطن في المشاهدة هـ ـ. }
\end{aligned}
$$

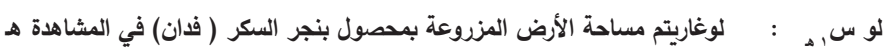

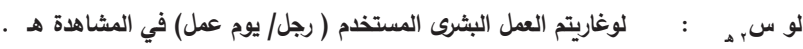

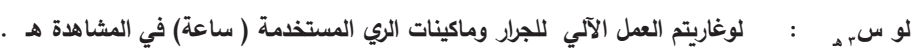

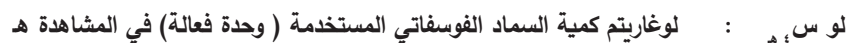

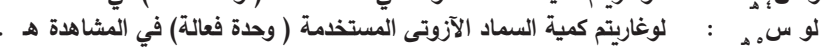

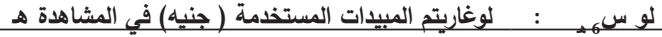




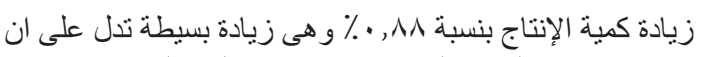

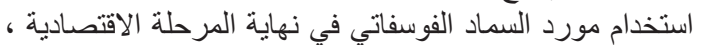

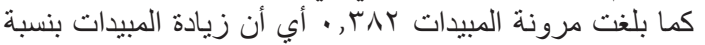

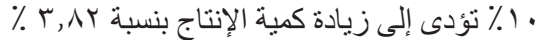

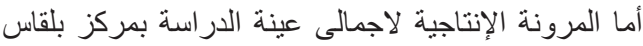

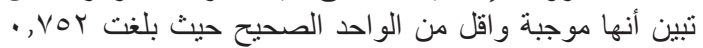

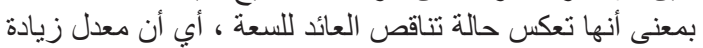

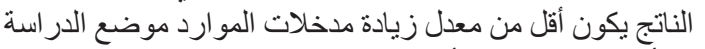

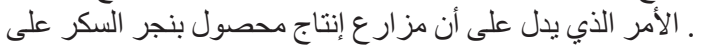

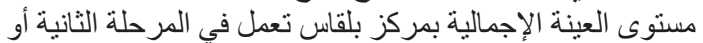
المرحلة الاقتصادية من مر احل الدالة الإنتاجية .

(ج) التقدير الاحصائى لدو ال إنتاج محصول بنجر السكر بمركز

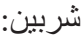

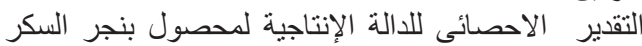
بالعروة الأولى : بتقدير الدالة الإنتاجية للعروة الأولى و الموضحة

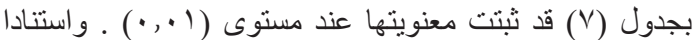

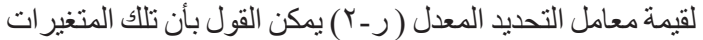
المستقلة مسئولة عن 90٪ للتغير ات التي يمكن حدوثها في الناتج

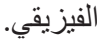

كما تبين أن أهم الددخلات الإنتاجية المؤثرة على كمية إنتاج

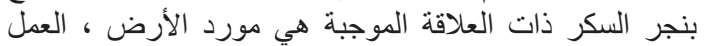

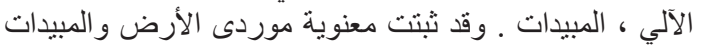

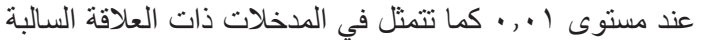

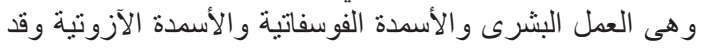

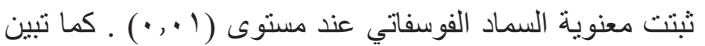

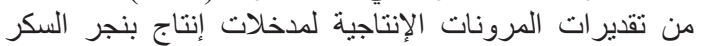

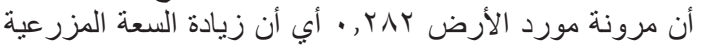
لمحصول بنجر السكر بنسبة ـ ـ ب بؤدى إلى زيادة في كمية إنتاج

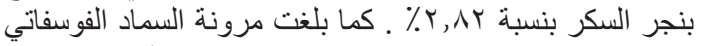

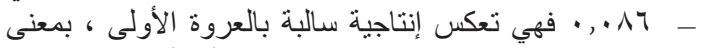

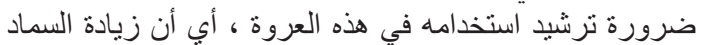

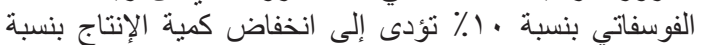

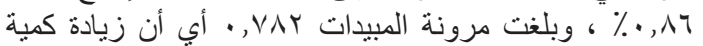

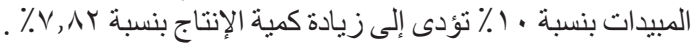

أما بالنسبة للمرونة الإنتاجية الإجمالية للعروة الأولى بمركز

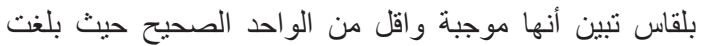

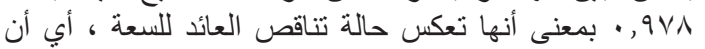

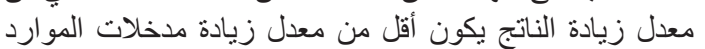

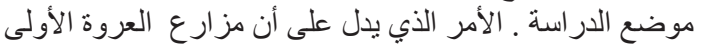

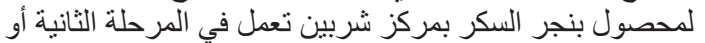
المرحلة الاقتصادية من مر احل الدالة الإنتاجية .

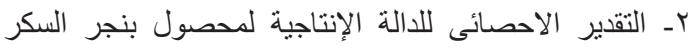

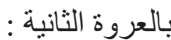

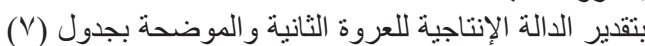

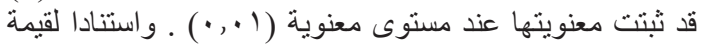

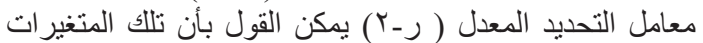

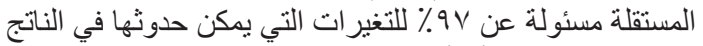
الفيزيقي. كما تبين أن أهم الدذخلات الإنتاجية المؤثرة على كمية لإنية

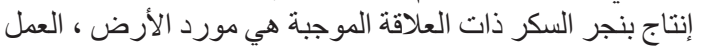

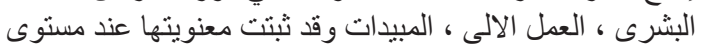

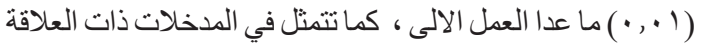

بالعروة الثالثة:

بتقدير الدالة الإنتاجية للعروة الثالثة والموضحة بجدول

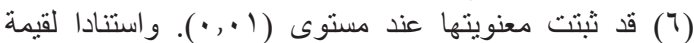

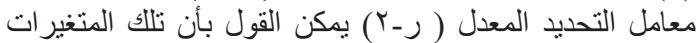

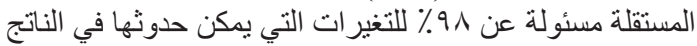

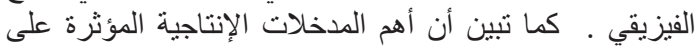

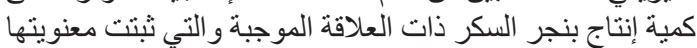

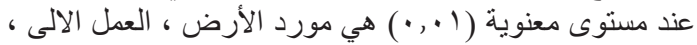

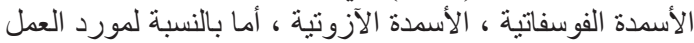

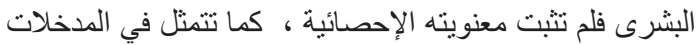

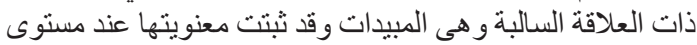

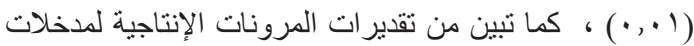

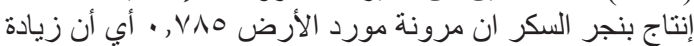

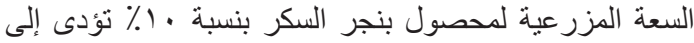

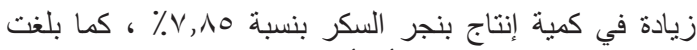

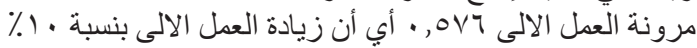

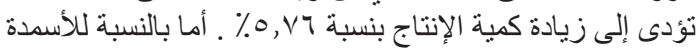

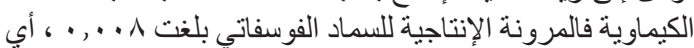

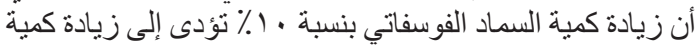

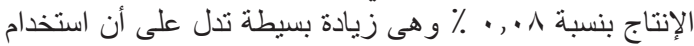

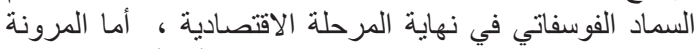

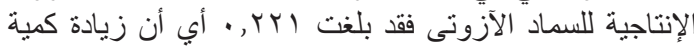

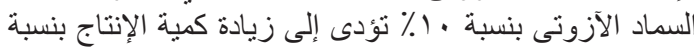

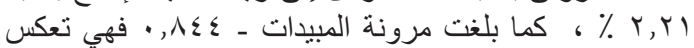

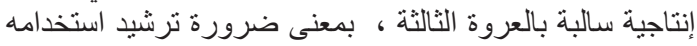

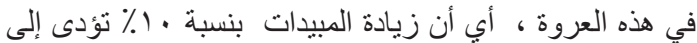

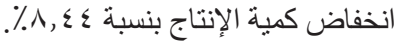

أما بالنسبة للمرونة الإنتاجية الإجمالية للعروة الثالثة بمركز

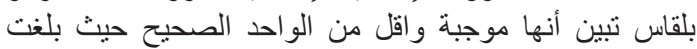

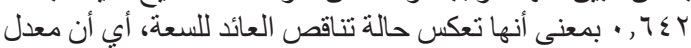

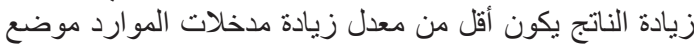

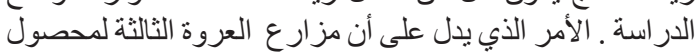
بنجر السكر بمركز بلقاس تعمل في المرحلة الثانية أو المرحلة الثرلة الاقتصادية من مر احل الدالة الإنتاجية .

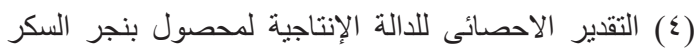

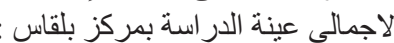

بتقدير الدالة الإنتاجية على مستوى اجمالى عينة الدراسة

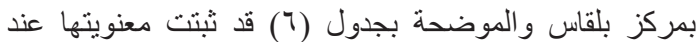

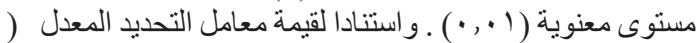

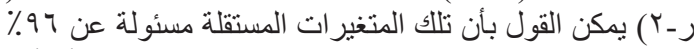

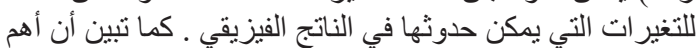

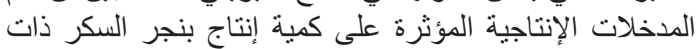

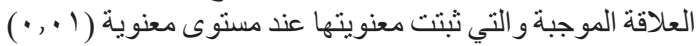

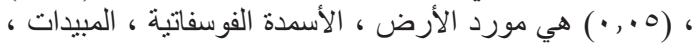

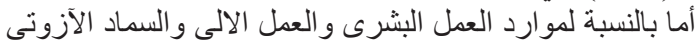

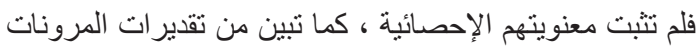

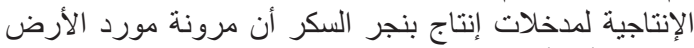

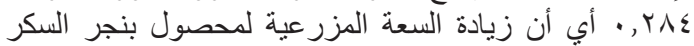

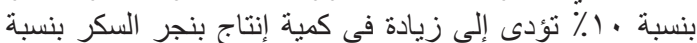

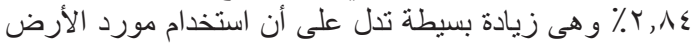

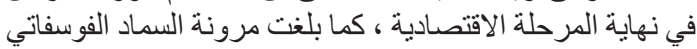

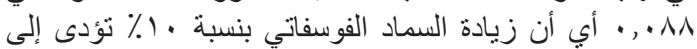




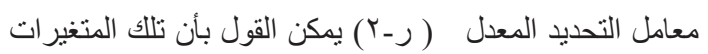

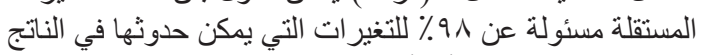

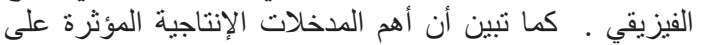

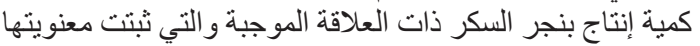

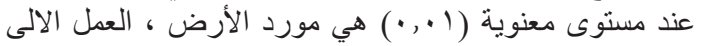

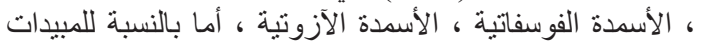

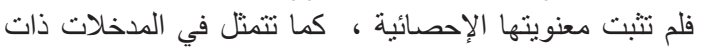

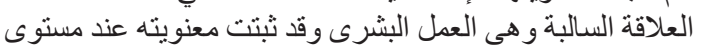

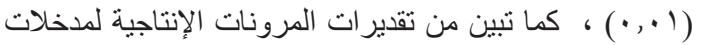

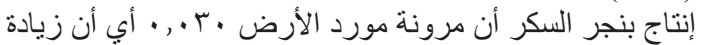

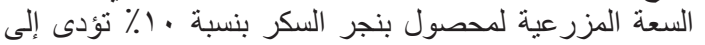

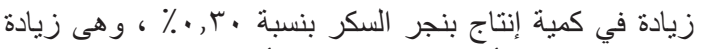

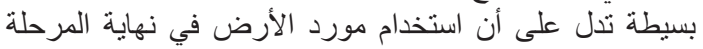

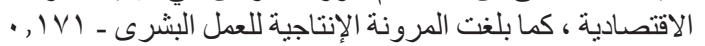

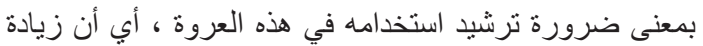

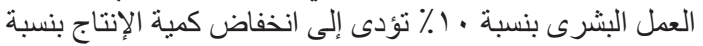

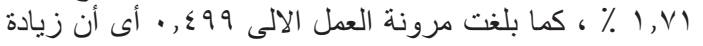

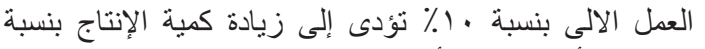

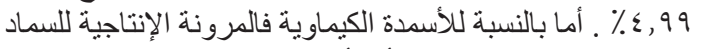

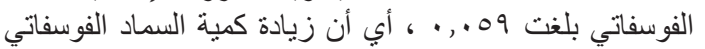

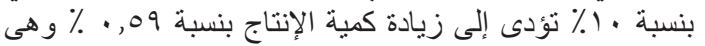

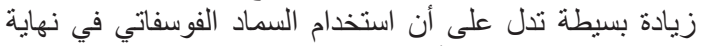

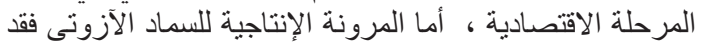

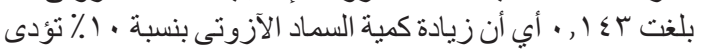

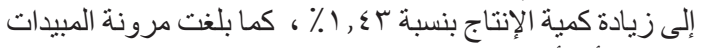

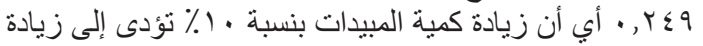

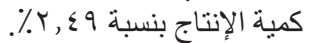

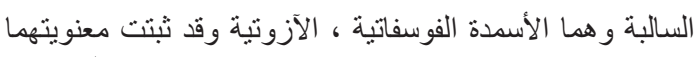

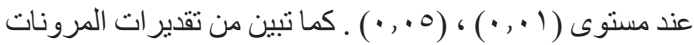

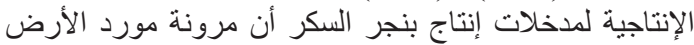

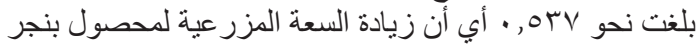

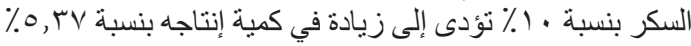

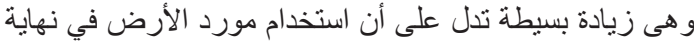

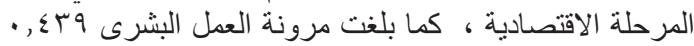

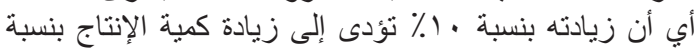

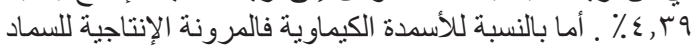

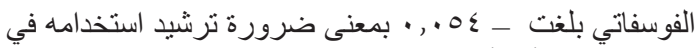

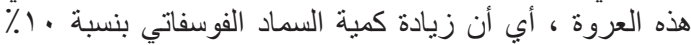

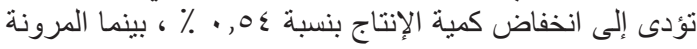

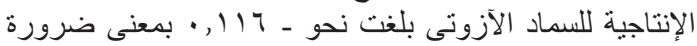

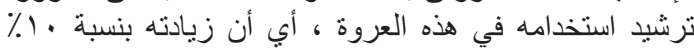

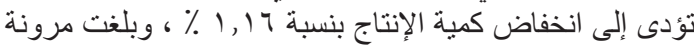

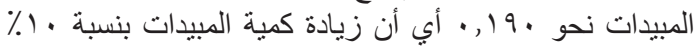

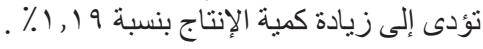

أما المرونة الإنتاجية الإجمالية للعروة الثانية تبين أنها موجبة التباتية

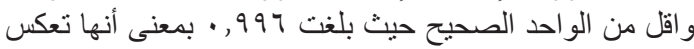

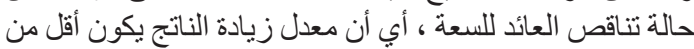

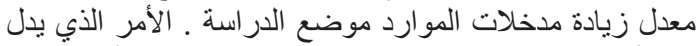

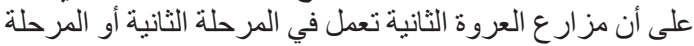

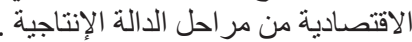

r- التقدير الاحصائى للدالة الإنتاجية لمحصول بنجر السكر

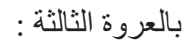

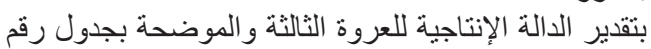
(V)

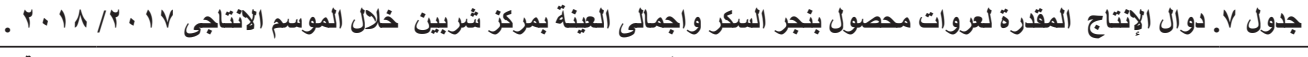

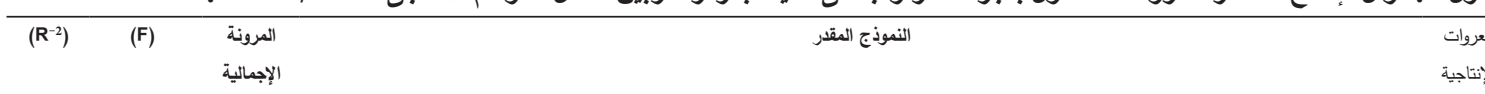

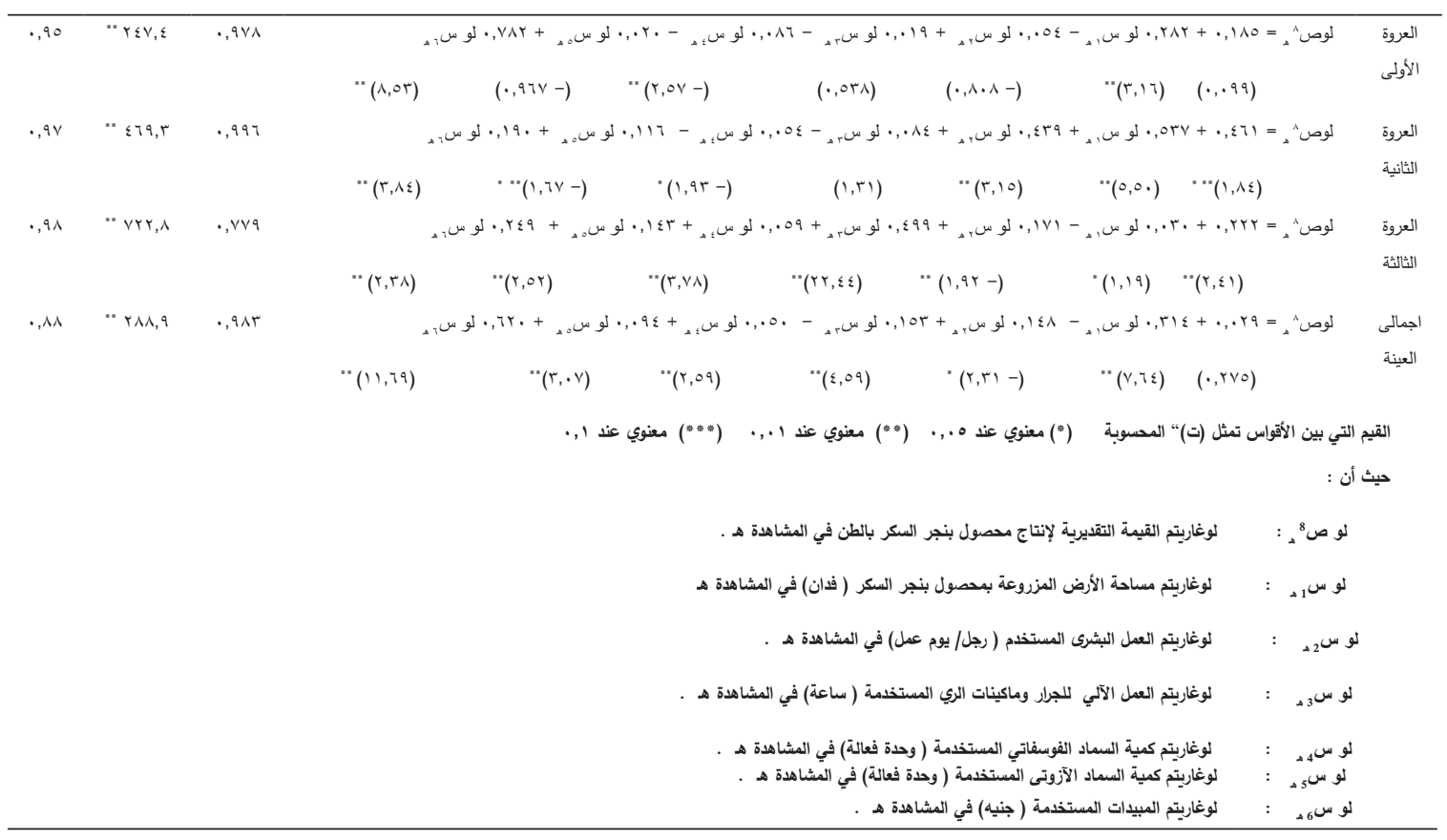

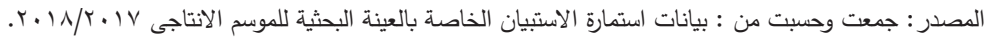

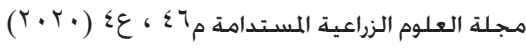


موضح بالجدولين (^) ، ( ) ( ) . وسيتم تناولهما على النحو التالي: 1 ـ متوسط تكلفة العمليات الإنتاجية:

توضح بيانات جدول (^) أن متوسط تكلفة إجر اء العمليات

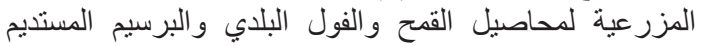

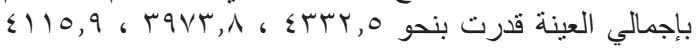

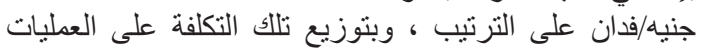

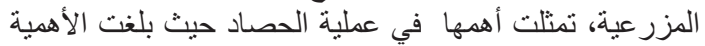

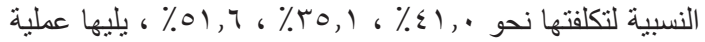

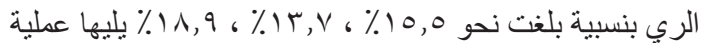

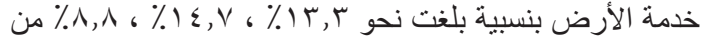
تكلفة العمليات المزر عية بالمحاصيل الثناث على الترتيب. r - متوسط أجور وقيمة المستلزمات الإنتاجية:

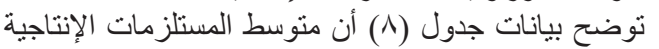

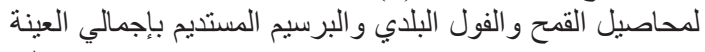

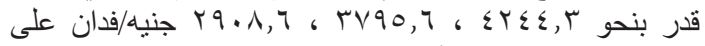
الترتيب . وبدراسة الأهمية النسبية لبنود مستلزمات الهات الإنتاج

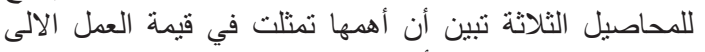

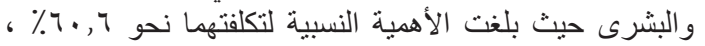

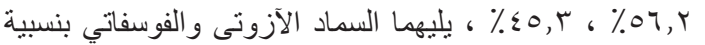

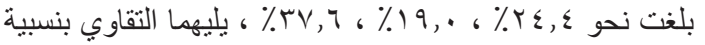

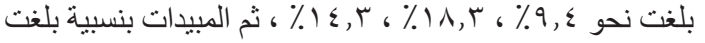

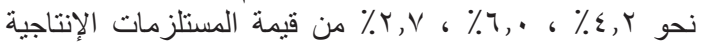

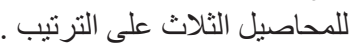

r- ـ صافى العائد الفدانى و عائد الجنيه المنفق: تبين بيانات جدول (9) أن منوسط الفئ التكاليف الإنتاجية الكلية

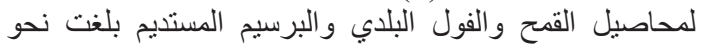

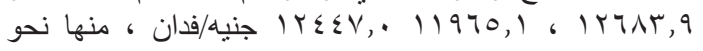

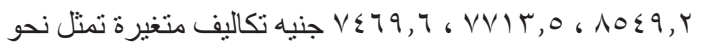
، ؛

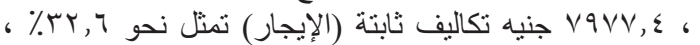

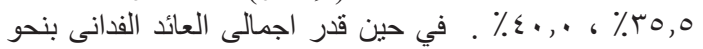

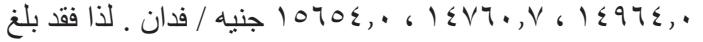

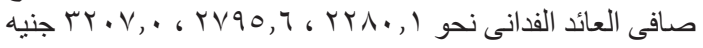

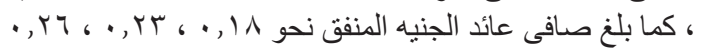
للمحاصيل الثتوية الثلاثة على التئ الترثيب .

خامسا: الملامح الاقتصادية لعروات إنتاج بنجر السكر بالمقارنة

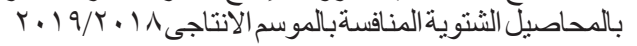

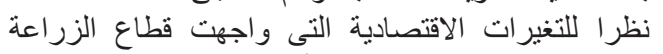

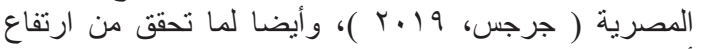

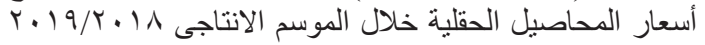

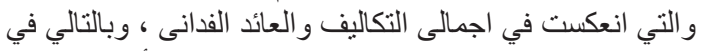

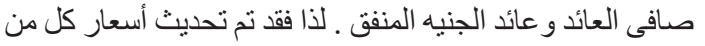

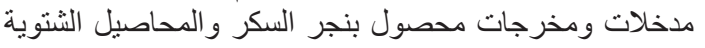

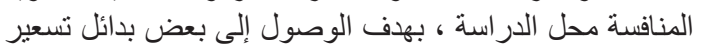

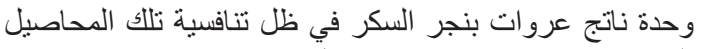

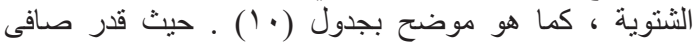

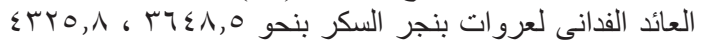

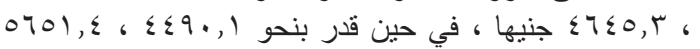

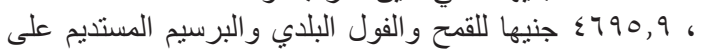

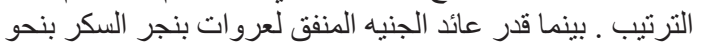

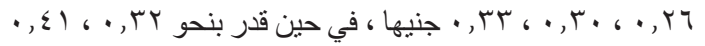

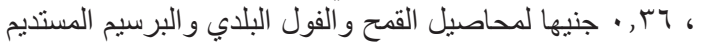

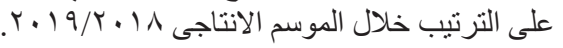

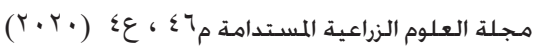

أما بالنسبة للمرونة الإنتاجية الإجمالية للعروة الثالثة بمركز

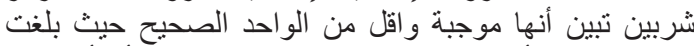
, VV9

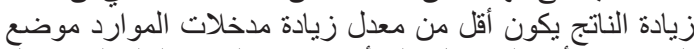

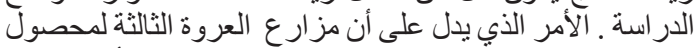

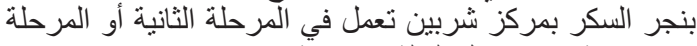

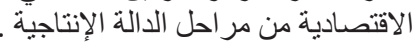

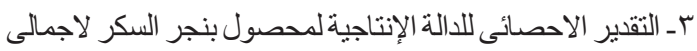

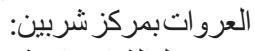

بتقدير الدالة الإنتاجية لإجمالي عينة الدراسة بمركز شركز شربين

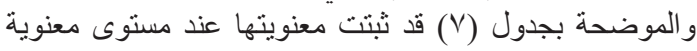

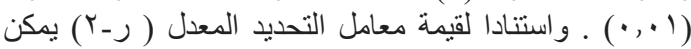

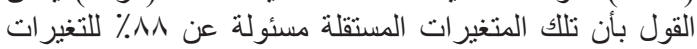

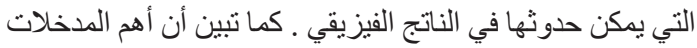

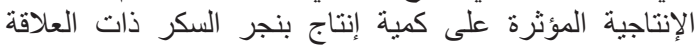

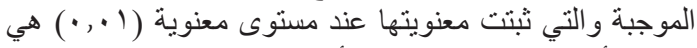

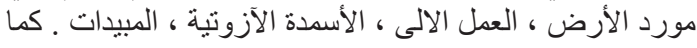

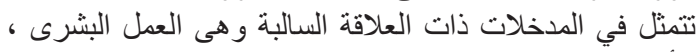

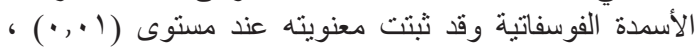

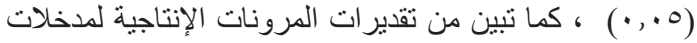

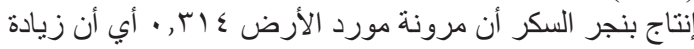

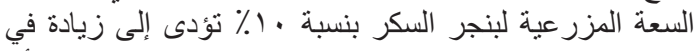

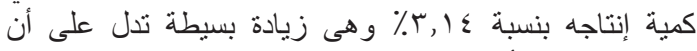

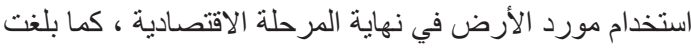

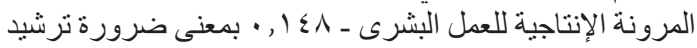

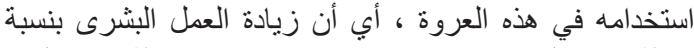

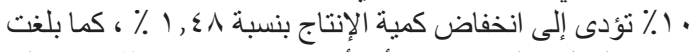

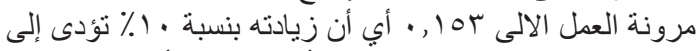

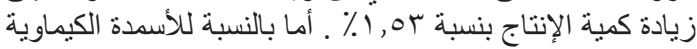

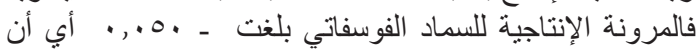

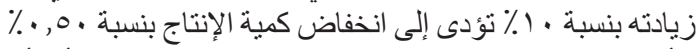

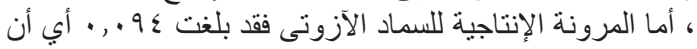

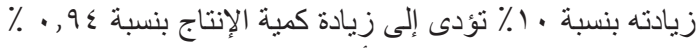

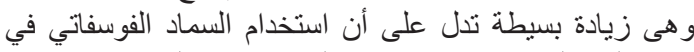

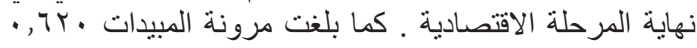

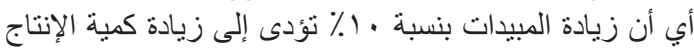

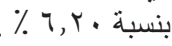

أما المرونة الإنتاجية لاجمالى عينة الدراسة بمركز شربين

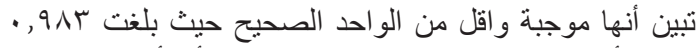

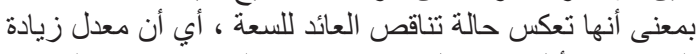

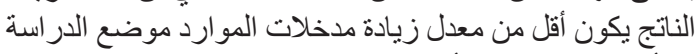

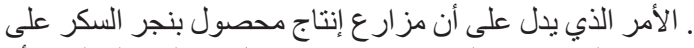

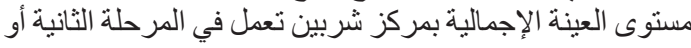
المرحلة الاقتصادية من مر احل الدالة الإنتاجية فئمئ.

رابعا:الملامح الاقتصادية لأهم المحاصيل الثنتوية المنافسة لعروات

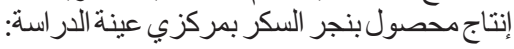

بتقدير تكاليف إنتاج المحاصيل الثنتوية (القمح و الفول البلدئي

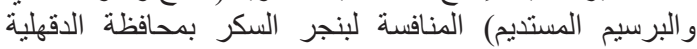

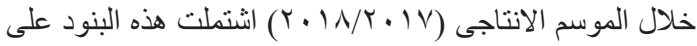

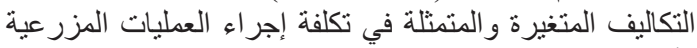

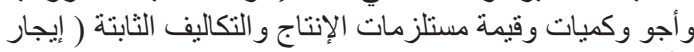

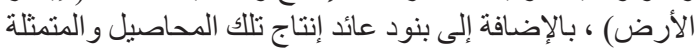

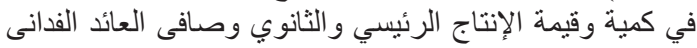

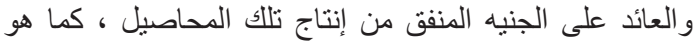




\begin{tabular}{|c|c|c|c|c|c|c|c|c|c|c|}
\hline جملة تكلفة & مصاريف & الحصاد " & مقاومة & الري & الكقل ونثر & الحمقاومة & الزراعة & خدمة الأرض & نقل ونثر السماد & البيان \\
\hline \multicolumn{11}{|c|}{ محصول القمح } \\
\hline$\varepsilon r \wedge r, \vee$ & Irr,q & IVqr,T & $\{1 \wedge, \uparrow$ & $7 \vee q, r$ & ITr, & rVo,T & $r \leq \cdot, \Lambda$ & 011,9 & Ir,V & بلقاس \\
\hline$\leq r \leq 9,7$ & $\mid r \leq, V$ & 1v07,1 & rᄉฯ,r & 707,1 & $1 \leq \Lambda, r$ & ro1, 9 & TMt, & otV,r & $11 \wedge, 7$ & شربين \\
\hline ETrT,O & $1 \times q, r$ & IVVT,O & $\varepsilon \cdot \varepsilon, q$ & $779, \wedge$ & $1 \Gamma \wedge, q$ & rฯq, \& & $r r v, 0$ & OVT, $\varepsilon$ & $1 r q, \wedge$ & العينة \\
\hline $1 \cdots$ & $r, \cdot$ & $\varepsilon 1$, & $9, r$ & 10,0 & $r, r$ & $7, r$ & 0,0 & r & $r$, & $\%$ \\
\hline \multicolumn{11}{|c|}{ محصول الفول البلدي } \\
\hline rᄉ90,乏 & $l \cdot V, r$ & $1 \leq \cdot r, 7$ & $\varepsilon 0 v, q$ & ort,r & $117, r$ & $\varepsilon \wedge 9, r$ & $r 10,1$ & $0 \leq r, V$ & $\Gamma_{0, \varepsilon}$ & بلقاس \\
\hline ए१ч & Iro, & $\mid r q \wedge, r$ & $\varepsilon r ฯ, \vee$ & $0 \leq 9,1$ & $1 \cdot \varepsilon, V$ & $01 Y, 7$ & $r T \varepsilon, r$ & $r \cdot r, \varepsilon$ & - & 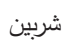 \\
\hline 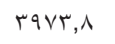 & $|r|, 0$ & $1 \varepsilon \cdot 1, \wedge$ & $\leq 01,7$ & $0 \leqslant r, \Lambda$ & $11 r, q$ & $0.9,1$ & rrq,V & ONT,A & 18,9 & العينة \\
\hline $1 \cdots$ & $r, 1$ & ro,r & $11, \varepsilon$ & Ir,V & $r, q$ & $M, \lambda$ & 0,1 & $1 \leqslant, V$ & $\cdot, \leq 0$ & $\%$ \\
\hline \multicolumn{11}{|c|}{ محصول البرسيم المستديم } \\
\hline$\varepsilon 1 r 0, r$ & $1 \cdot r, q$ & סיט, & - & $\Lambda \cdot r, \varepsilon$ & 90,7 & $01 r, 7$ & $11 r, 7$ & $r v \varepsilon, T$ & - & بلقاس \\
\hline$\varepsilon \cdot \wedge \neg, \vee$ & $\wedge r, v$ & $Y 117, \varepsilon$ & $1 \cdot r, 0$ & vol, & $1 \cdot \varepsilon, r$ & $\leqslant 79,0$ & $1.0,1$ & ror, & - & شربين \\
\hline$\leq 110,9$ & $9 \leqslant, 1$ & rIro,r & $01, r$ & $V \vee \wedge, r$ & $1 \cdot 1, r$ & $\varepsilon q r, 1$ & 11.r & שדיז & - & العينة \\
\hline $1 \ldots$ & $r, r$ & 01,7 & $1, r$ & 11,9 & $r, 0$ & ${ }_{1}, \cdot$ & $r, V$ & $\wedge, \wedge$ & - & $\%$ \\
\hline
\end{tabular}

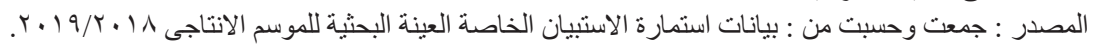

تابع جدول ^. متوسط أجور وكميات وقيم مستلزمات الإتتاج لأهم المحاصيل الشتوية المنافسة لمحصول بنجر السكر بمركزي عينة الدراسة خلال (جنيه/فنان)

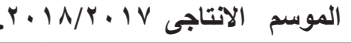

\begin{tabular}{|c|c|c|c|c|c|c|c|c|c|c|c|}
\hline & \\
\hline \multirow{2}{*}{ المستلزماتى } & \multirow{2}{*}{ قيمة العمل الالى و } & \multirow{2}{*}{ قالمبيدات } & \multicolumn{2}{|c|}{ السماد الآزوتى } & \multicolumn{2}{|c|}{ سوبر فوسفات } & \multicolumn{2}{|c|}{ التقاوي } & \multicolumn{2}{|c|}{ السماد البلاي } & \multirow[b]{2}{*}{ البيان } \\
\hline & & & 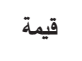 & وحدة & قيمة & وحدة & قيمة & 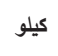 & قيمة & $r^{b}$ & \\
\hline \multicolumn{12}{|c|}{ محصول القمـح } \\
\hline 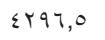 & YTY & $110, r$ & $\Lambda \leq 0, V$ & $T V, 1$ & $171, \mathrm{~V}$ & $M, 0$ & ¿ा & 09 & $7 V, 7$ & $r, \varepsilon$ & بلقاس \\
\hline$\sum 17 \wedge, 9$ & Y017,0 & $17 r, 9$ & טד, & $V \cdot, r$ & $194, \varepsilon$ & $1 \leq, r$ & rлt & 00 & $\leqslant q, \varepsilon$ & 1,9 & شربين \\
\hline$\varepsilon r \leq \varepsilon, r$ & rovr,T & $1 V 7,0$ & $107, \mathrm{~V}$ & 79,1 & IV^,q & T, & ए११ & $0 \wedge$ & 09,7 & $r, r$ & العينة \\
\hline $1 \ldots$ & $7 \cdot 7$ & $\varepsilon, r$ & $r \cdot, r$ & - & $\varepsilon, r$ & - & $q, \varepsilon$ & - & $1, \varepsilon$ & - & $\%$ \\
\hline \multicolumn{12}{|c|}{ محصول الفول البلدي } \\
\hline$r \vee \leq \wedge, \varepsilon$ & rirq,0 & $r \mid \leq, r$ & $\varepsilon \cdot r, q$ & rr,A & $r V \leq, r$ & $r), 0$ & 710 & $7 \wedge$ & $r 1,0$ & $1, r$ & بلقاس \\
\hline rN)v,т & riro,r & rrד,O & rov, & $r \cdot, 0$ & $r 90,1$ & r & $v \cdot r$ & $V \varepsilon$ & - & - & شربين \\
\hline rvq0,T & TITs,0 & TYV, & rᄉґ,т & ri,q & עזי, & $r V, \Lambda$ & 797 & VY & 17,9 & $\cdot, \wedge$ & العينة \\
\hline $1 \ldots$ & $07, r$ & $7, \cdot$ & $1 \cdot, 1$ & - & $\wedge, 9$ & - & $1 \wedge, r$ & - & $\cdot, \leqslant 0$ & - & $\%$ \\
\hline \multicolumn{12}{|c|}{ محصول البرسيم المستديم } \\
\hline หЯ7т,१ & $1 \pi \leqslant v, \varepsilon$ & $\Delta r, v$ & 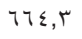 & $0 \leqslant, 9$ & $\varepsilon r v, 0$ & ro,r & $\varepsilon r$. & rV & - & - & بلقاس \\
\hline ץヘזะ,7 & I rᄉษ,r & 81,9 & $\vee \circ 9, \wedge$ & $T r, V$ & rT.,T & $r \leqslant, \Lambda$ & r97 & ro & - & - & شربين \\
\hline$r q \cdot \wedge, 7$ & $|r| \wedge, q$ & $\vee \wedge, T$ & VIT,A & 09,9 & rᄉ , , & $r_{1,0}$ & $\leqslant 10$ & ry & - & - & العينة \\
\hline $1 \cdots$, & $\leq 0, r$ & $r, V$ & $r \varepsilon, 0$ & - & $1 r, 1$ & - & $1 \leqslant, r$ & - & - & - & $\%$ \\
\hline
\end{tabular}

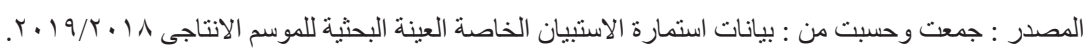

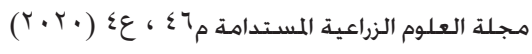




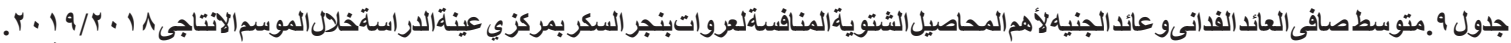
(جنيه/فدان)

\begin{tabular}{|c|c|c|c|c|c|c|c|c|c|c|}
\hline الجنيه & صافى العائد & الإيراد الكلى & الثاناتوي & قيمة & ساتج الرئب & أربب & التكاليف & قيمة الإيجار & 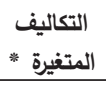 & البيان \\
\hline \multicolumn{11}{|c|}{ محصول القمح } \\
\hline$\cdot, I V$ & YMA, \& & $1 \leq 777,9$ & $\leqslant 00 \cdot, V$ & $1.117, r$ & oor,, & $1 \wedge, r$ & Irors,o & $\varepsilon \mid r_{\cdot, \cdot}$ & $\wedge \leqslant 1 \wedge, 0$ & شربين \\
\hline$\cdot, 11$ & rrג., I & $1 \leq 97 \leq$, & $\varepsilon \pi r \cdot, 0$ & $1 \cdot r \leq r, 0$ & 007,1 & $1 \wedge, 7$ & IrצAr,q & $\varepsilon \| \leqslant, V$ & $10 \leqslant 9, r$ & العينة \\
\hline \multicolumn{11}{|c|}{ محصول الفول البلدي } \\
\hline דו, & r & $10 . r \varepsilon, 1$ & $1 \pi \mid 1, r$ & I MVYr,q & IVAr,r & $\mathrm{v}, \mathrm{V}$ & $119 r r, \wedge$ & $\varepsilon \curlyvee \wedge 9, \cdot$ & $\vee \neg \varepsilon r, \wedge$ & بلقاس \\
\hline$\cdot, r_{\cdot}$ & $r \leq \cdot \leq, V$ & $1 \leq r q \wedge, 7$ & וצד, & . & IVvo,. & $\vee, \varepsilon$ & 11994,9 & EYा,. & $\vee \vee \wedge 1, q$ & شربين \\
\hline • & $r \vee 90,7$ & $1 \leqslant V 7 \cdot, V$ & Iror,r & Wo. , & 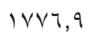 & $v, r$ & 11970,1 & $\varepsilon r 01,7$ & VVIT,O & العينة \\
\hline$\cdot, r \leq$ & $r q .0,7$ & $10 r 00,7$ & - & $10 r 00,7$ & rᄉוr,q & $\varepsilon$ & irro. & ะ97^,1 & VrیI,q & شربين \\
\hline דו, & $r r \cdot V, \cdot$ & $1070 \leqslant$, & $\cdot, \cdot$ & $1070 \leqslant$, & एवाт,० & $\varepsilon$, & $M \leq \leqslant V$, & $\varepsilon q \vee \vee, \varepsilon$ & $V \leq 79,7$ & العينة \\
\hline
\end{tabular}

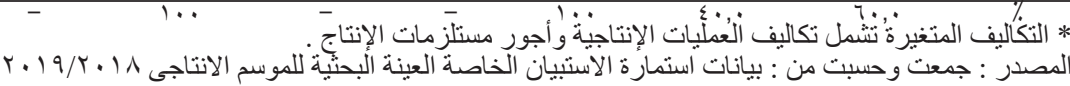

جدول · ا ـ متوسط صافى العائد وعائد الجنيه لعروات بنجر السكر والمحاصيل الثتوية المنافسة بمركزي عينة الدراسة لموسم 1 ـ ب/9 1 ـ ؟ . (جنيه/ف)

\begin{tabular}{|c|c|c|c|c|c|c|c|c|c|c|}
\hline الجنيائ & صافى العائد & الإيراد الكلى & الثاتاتج & قيمة & سعر الناتج & أردب & التكاليف & قالإيجارة & التكاليف & البيان \\
\hline \multicolumn{11}{|c|}{ العروة الأولى . } \\
\hline$\cdot$, ro & $r \leqslant r q, 1$ & $l v \leqslant v \cdot r$ & Ү৭१^, \& & $1 \leq \leqslant \vee 1, q$ & VIr,q & $r \cdot, r$ & $1 \leq \cdot r \mid, r$ & $01 K r, q$ & $\wedge q \cdot \vee, r$ & بلقاس \\
\hline$\cdot, Y V$ & $r V v \cdot, q$ & IV079,V & $r \leq .1, r$ & $10171, \varepsilon$ & $790, \wedge$ & $r, \Lambda$ & 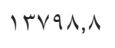 & $0107, r$ & $\wedge T \leqslant r, 0$ & شربين \\
\hline \multirow[t]{2}{*}{ דוY, } & $\Gamma ч \Lambda \wedge, 0$ & IVoro,r & $r v \ldots, r$ & $1 \leqslant \wedge 70$, & $V \cdot \varepsilon, 0$ & r), & $1 \% q 17, \vee$ & $01 \leqslant 1,0$ & AVVO, r & العينة \\
\hline & - & - & - & - & - & - & $1 \ldots$ & rד, & 1 & $\%$ \\
\hline \multicolumn{11}{|c|}{ العروة الثانية } \\
\hline$\cdot, r$ & $\varepsilon \varepsilon r r, q$ & 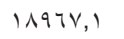 & r. 1,0 & 17770,7 & $779, r$ & $r \varepsilon, q$ & ו & $0 \leqslant 1 \vee, q$ & $9110, r$ & بلقاس \\
\hline$\cdot, r q$ & $\varepsilon r \cdot \varepsilon, r$ & 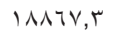 & $r \leq 97,1$ & $17 r v 1, r$ & גוצ,ג & $r \leqslant, V$ & 1 $\leqslant 77 r, 1$ & צודצות & 9rru,v & شربين \\
\hline \multirow[t]{2}{*}{$\cdot, r}$. & EMro,A & 11990,0 & $r \leq \cdot 1, r$ & $170 Y \leqslant, r$ & & $r \leqslant, \Lambda$ & $1 \leqslant 099, \vee$ & orvv, t & Grrr, & العينة \\
\hline & - & - & - & - & - & - & $1 \ldots$ & rד, & r & $\%$ \\
\hline \multicolumn{11}{|c|}{ العروة الثالثة } \\
\hline$\cdot, r \varepsilon$ & $\varepsilon \vee r \Psi, 0$ & $1 \wedge \wedge \leq 7,9$ & rYqY,r & $1700 \leqslant, 7$ & $T \leq q, r$ & $r_{0,0}$ & $1 \leqslant 11 \cdot, 0$ & O & 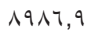 & بلقاس \\
\hline r & $\varepsilon \leqslant \wedge 9,0$ & $110 . r_{1}$ & rYA.,A & ITYKI,Y & $T \leq r, V$ & $r_{0, r}$ & $1 \varepsilon \cdot 1 r, 0$ & $0110, r$ & AAYV,r & شربين \\
\hline שTr, & $\leq \nearrow \leq 0, r$ & IAVT., & rYAq & $17 \leq r \mid, r$ & $7 \leq 7,9$ & $r_{0, \varepsilon}$ & $1 \varepsilon \cdot v 0,1$ & 0109,1 & 1910,r & العينة \\
\hline- & - & - & - & - & - & - & $1 \ldots$ & $r 4, V$ & ז,זיד & $\%$ \\
\hline \multicolumn{11}{|c|}{ محصول القمح } \\
\hline$\cdot, r$. & $\leq r \mid 9, \wedge$ & $1 \wedge r \vee q, q$ & $079 \leq, \varepsilon$ & Iro10,0 & 770,9 & 11,9 & $1 \varepsilon \cdot 7 \cdot, 1$ & $0.70, \varepsilon$ & 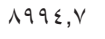 & بلقاس \\
\hline$\cdot r \varepsilon$ & $\sum V T^{\prime}, 0$ & 11074,9 & OVYI,Y & $\mid r \wedge \leq Y, V$ & $70 \wedge, 7$ & 19,0 & 1 & $0.91,1$ & AVII, T & شربين \\
\hline ש & $\leq \leqslant 9 \cdot, 1$ & $|\wedge \leq r|, q$ & $O V \cdot r, \Lambda$ & $|r V| \Lambda, 1$ & TYY,\& & $19, r$ & גו"ג & $0 . V V, r$ & $\wedge \wedge 0 \leqslant, 1$ & العينة \\
\hline- & - & - & - & - & - & - & $1 \ldots$ & (צ, & צז, & $\%$ \\
\hline \multicolumn{11}{|c|}{ محصول الفول البلدي } \\
\hline$\cdot, \mathrm{rA}$ & orrq,V & 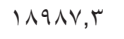 & דוז, & IVTY $\leqslant, V$ & $r 00 \leqslant, r$ & 7,9 & Irvov, T & 0794,1 & $\Lambda \cdot T \leqslant, 0$ & 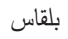 \\
\hline$\cdot, \leqslant \varepsilon$ & $7.7 \cdot, 0$ & $19117, \varepsilon$ & $1+90, \varepsilon$ & $|A \leq r|, \cdot$ & r०q $\leqslant, 0$ & $v, 1$ & $1 r v 00, q$ & oor, $\mathrm{V}$ & $\Delta r \mid V, r$ & شربين \\
\hline$\cdot, \leqslant 1$ & $0701,\{$ & $19 \leq \cdot \wedge, r$ & $|r \wedge|, r$ & $|\Lambda \cdot r v|$, & rovo,r & $\mathrm{v}, \cdot$ & irvor, 9 & $071 \leqslant, r$ & $\lambda) \leq r, T$ & 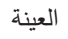 \\
\hline- & - & - & - & - & - & - & $1 \cdots$ & $\varepsilon \cdot, \wedge$ & $09, r$ & $\%$ \\
\hline \multicolumn{11}{|c|}{ محصول البرسيم المستديم } \\
\hline$\cdot$, ro & $\{000,1$ & IVI $\{9, r$ & - & $\mid V T \leq q, r$ & $\varepsilon \varepsilon \mid r, r$ & $\varepsilon$ & $1 \% \cdot 9 r, \varepsilon$ & $00 \leqslant 7,9$ & Vo $\{7,0$ & 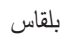 \\
\hline$\cdot$, rA & $\varepsilon \wedge r \vee, 1$ & $1 \vee Y \cdot V, T$ & - & IVT.V,T & $\varepsilon \varepsilon \cdot 1,9$ & $\varepsilon$ & IrVA.,o & orq^, 7 & VrNI, 9 & شربين \\
\hline דיז, & $\leqslant 790,9$ & IVTrT,Y & . & IVTr, & $\varepsilon \varepsilon \cdot \wedge, r$ & $\varepsilon$ & IYqRV,r & $0 \leq \vee 1, \varepsilon$ & $V \leqslant 70,9$ & العينة \\
\hline- & - & - & - & - & - & - & $1 \ldots$ & or, r & $O V, V$ & $\%$ \\
\hline
\end{tabular}

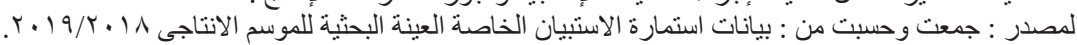

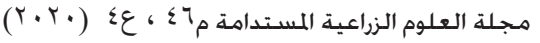




$$
\text { موضح بجدول (1 (1) ) وسيتم تناولها على النحو التنالي : }
$$

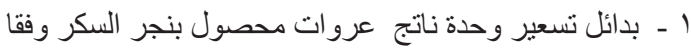

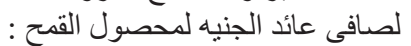

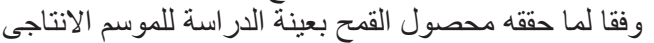

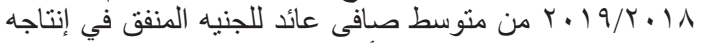

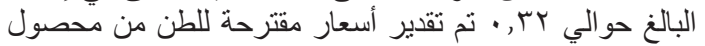

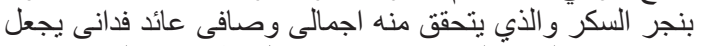
صافى عائد الجنبة المنفق في إنتاجه بعادل نظيره من القمح ، بلى حيث

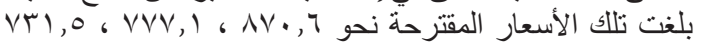
جنيها للطن بالعروات الإنتاجية الأولى الثاني الثاني الثالثة على الترتيب

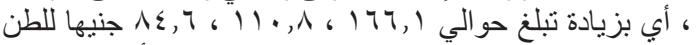

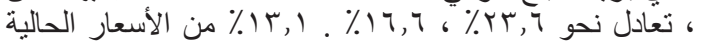

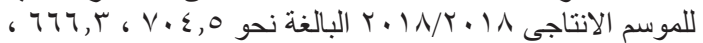

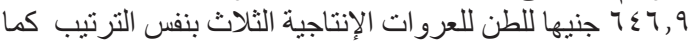

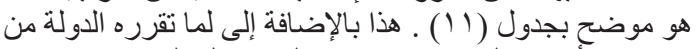

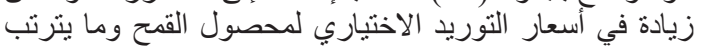

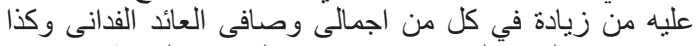
صافى عائد الجنيه المنفق في إنتاجه في السنو ات القادمة

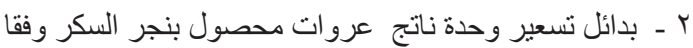

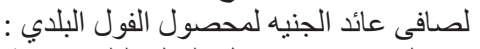

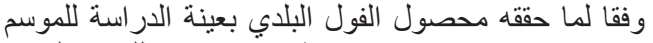

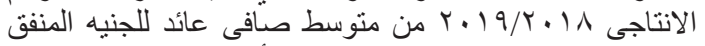

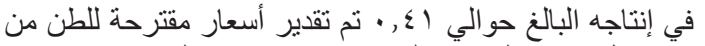

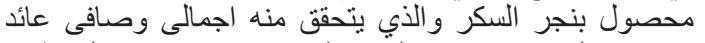

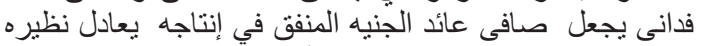

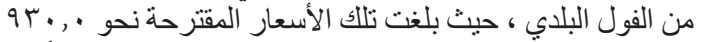

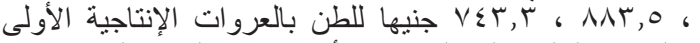

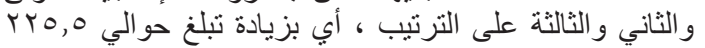

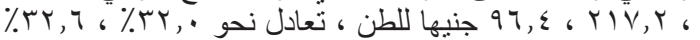

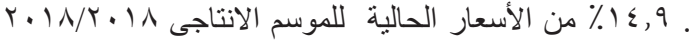

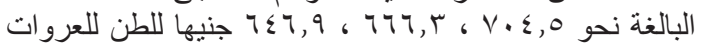

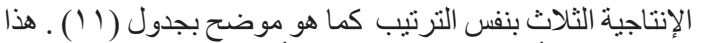

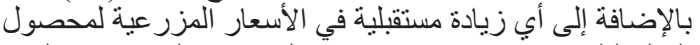

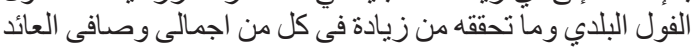
الفدانى وكذا صافى عائد الجنيه المنفق في إنتاجه في السنوات التحات

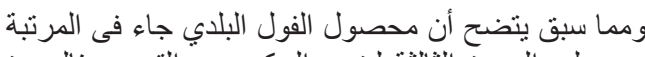

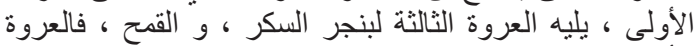

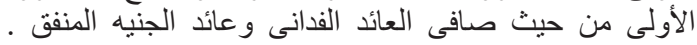

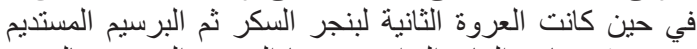

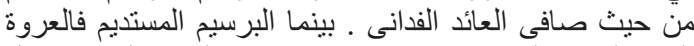

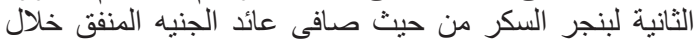

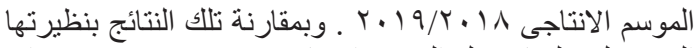

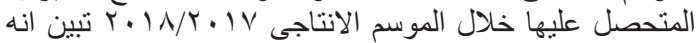

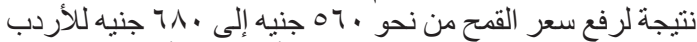
اللموسمين الإنتاجيين سالفى الذكر ـ الأمر الذي أدى إلى النى ارتفاع

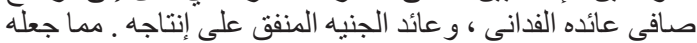

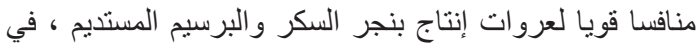
حين ظل الفول البلادي في صدارة الدحاصيل الثنتوية المنافسة. سادسا: بدائل تسعير وحدة ناتج عروات محصول بنجر السكر فى لئ ظل تنافسية أهم المحاصيل الثنتوية

على الرغم من احتكار شركة الدلتا للسكر شراء التهر محصول

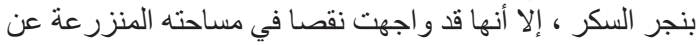

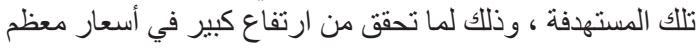

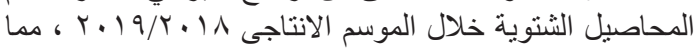

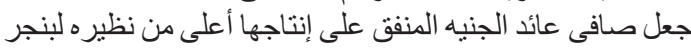

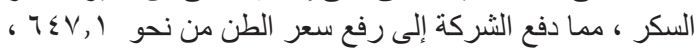

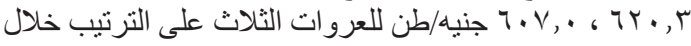

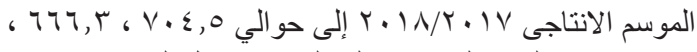

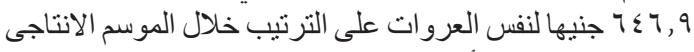

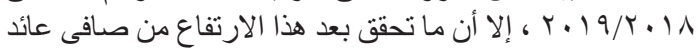

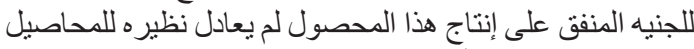

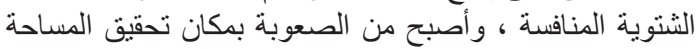
المستهدف زر اعتها لتشغيل مصان الثركة بكامل طاقتها ـ

لذا يهدف هذا الجزء من الدراسة إلى وضع بدائل مقترحة

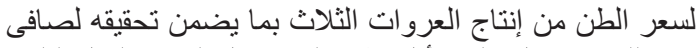

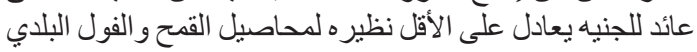

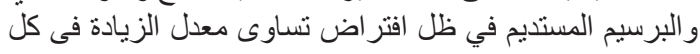

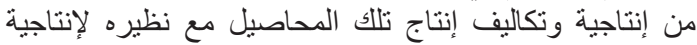
وتكاليف محصول بنجر السكر خلال السنوات القادمة . كما هو لإنية

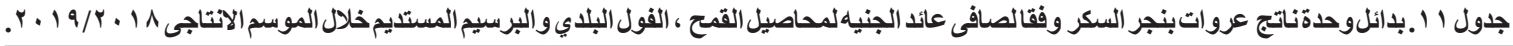

\begin{tabular}{|c|c|c|c|c|c|c|c|}
\hline ا التغير & مقدار التغير & السعر الحالى للطن & السعر المقترح & صافى العائد & اجمالى العائد & التكاليف الكلية & العروة \\
\hline \multicolumn{8}{|c|}{ محصول القـح } \\
\hline$r r, r$ & 174,1 & $V \cdot \varepsilon, 0$ & $\lambda v \cdot, \tau$ & $\varepsilon \varepsilon 0 r, r$ & IArV.,. & $14917, v$ & الأولى \\
\hline 17,7 & $11 \cdot, \lambda$ & זיזוד & $v \checkmark v, 1$ & $\leq 7 \times 1,9$ & $19 Y V 1,7$ & $1 \leqslant 099, \vee$ & الثانية \\
\hline $\mid r, 1$ & $\wedge \varepsilon, 7$ & $7 \leq 7,9$ & $V T_{1,0}$ & $\varepsilon 0, \varepsilon$, & $110 \vee 9,1$ & $1 \leq \cdot v_{0}, 1$ & الثالثة \\
\hline \multicolumn{8}{|c|}{ محصول الفول البلاي } \\
\hline rr., & rro,o & $V \cdot \varepsilon, 0$ & q५.,. & $0 V \cdot 0,1$ & 197rr,o & $14917, v$ & الأولى \\
\hline r & rIV,r & תוז, & AMr,o & 0910,9 & $r .010,7$ & $1 \leqslant 099, \vee$ & 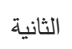 \\
\hline $1 \leqslant, 9$ & $97, \varepsilon$ & $7 \leq 7,9$ & $v \leqslant r, r$ & orve, A & $19 \wedge \leq 0,9$ & $1 \varepsilon \cdot v_{0}, 1$ & 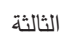 \\
\hline \multicolumn{8}{|c|}{ محصول البرسيم المستديم } \\
\hline$r v, r$ & 194,0 & $V \cdot \varepsilon, 0$ & $\wedge q \vee,$. & $0.1 \cdot, \cdot$. & । $19 \curlyvee 4, V$ & $14917, v$ & الأولى \\
\hline$r v, q$ & 1100,9 & r & Nor,r & oroo, 9 & 19100,7 & $1 \leqslant 099, V$ & الثانية \\
\hline $1,1,1$ & $v \ldots$ & $7 \leqslant 7,9$ & V) 7.9 & $0.7 \mathrm{V.}$. & $|q| \leqslant r, 1$ & $1 \varepsilon \cdot V_{0} \mid$ & الثالثة \\
\hline
\end{tabular}

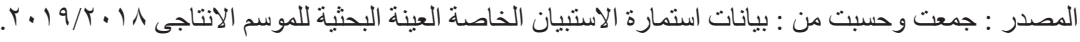




\section{المراجع}

السعدي ، أحمد بدير ، محمد مصطفى خلبفة ، مصطفى عبدربه

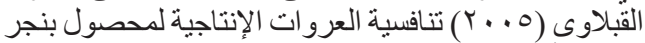

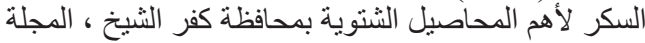

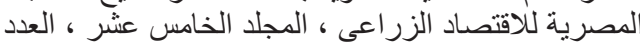

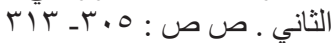

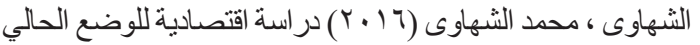

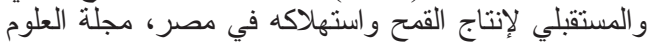

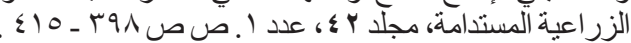

النفيلى ، الحسيني احمد ، طارق محمد أبو موسى (9 ( م ب)در اسة الإنة

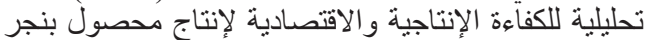

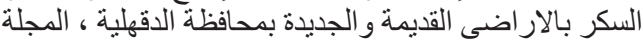

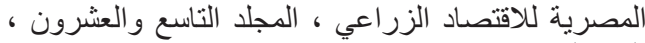

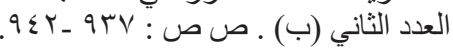

جرجس ، مرفت روفائيل (9 1 ـ ب) دراسة تحليلية لاستجابة أهم

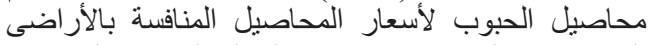

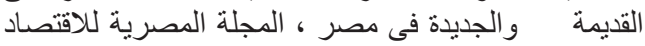

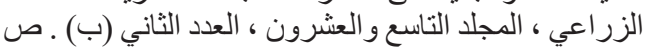

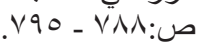

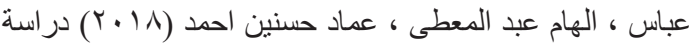

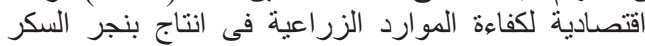

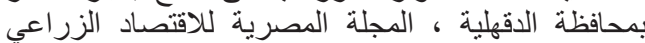

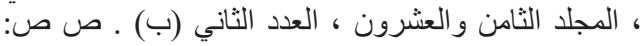
1.09 - 1.01

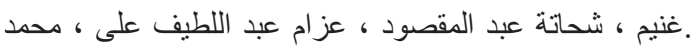

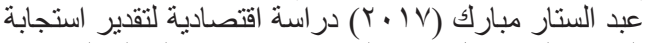

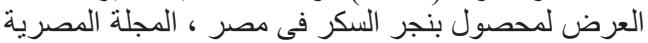

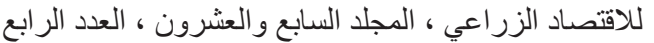

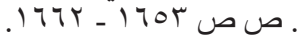

محافظة الدقهلية ، مركز المعلومات ودعم اتخاذ القرار ، بيانات

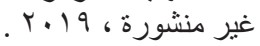

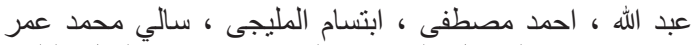

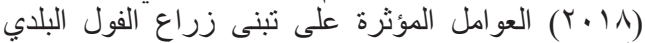

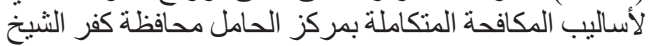

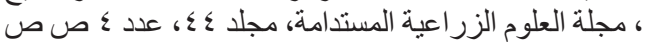
r r Y _ r.

محافظة الدقهلية ، مركز المعلومات ودعم اتخاذ القرار ، بيانات

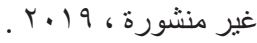

فو از، محمود محمد ، كريمة زكريا سبد أحمد ، أية محمد زعفان (Y. IN)

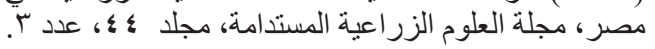
ص ص ص: VN - IV

محجوب ، زينب عمر (19 + (Y) محددات إنتاج محصول بنجر

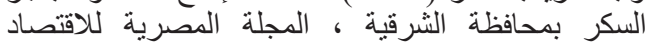

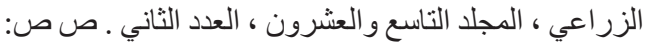
हr। - \&19

وز ارة الزر اعة واستصلاح الار اضى ، مديرية الزر اعة بالدقهلية

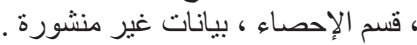

وزارة الزر اعة واستصلاح الار اضي ، قطاع الشئون الاقتصادية

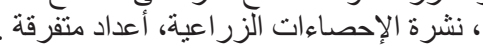

r - - بدائل تسعير وحدة ناتج عروات محصول بنجر السكر وفقا لصافى عائد الجنيه للبرسيم المستديم : لـاتئ

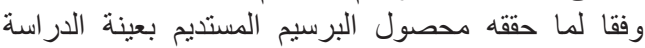

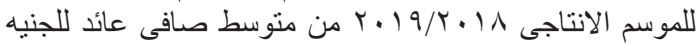
المنفق في إنتاجه البالغ حو الي بس ، • • تم تقدير أسعار مقترحة للطن

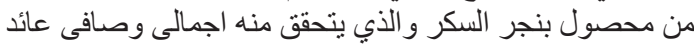

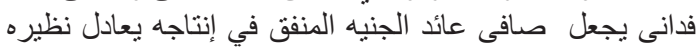

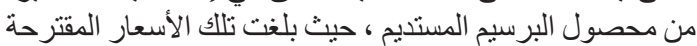

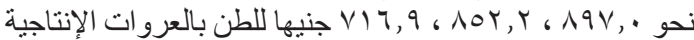
الأولى والثاني والثالثة على الترثيب ، أبي بزيادة ثبلغ حوالي ، التي

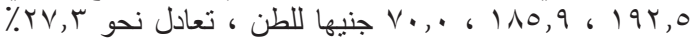
،

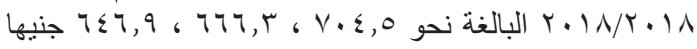

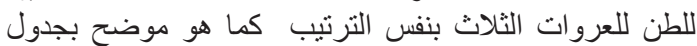

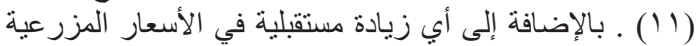

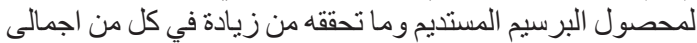
وصافى العائد الفدانى وكذا صافى عائد الجنيه المنفق في إنتاجه

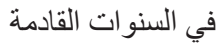

ومما سبق يتضح أن محاصبل القمح و الفول البلدي و البرسيم

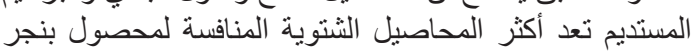

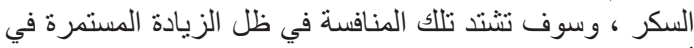

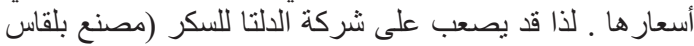

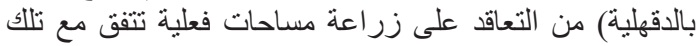

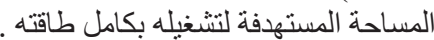

وبناءا على النتائج التي توصلت الدراسة فإنها توصىى بما يلي:

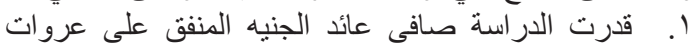

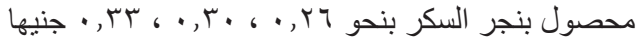

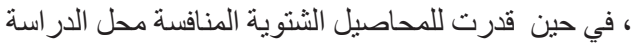

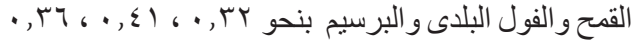

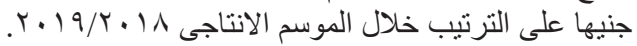

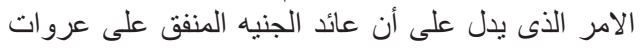

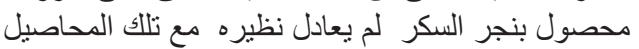
ـ لذا يجب على شركة الالتا للسكر (مصنع بلقاس بمحافظة الدقهلية) إقرار زيادة مستمرة فى سعر توريده ، حتى ثتمكن

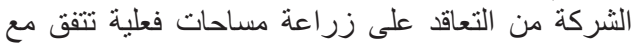

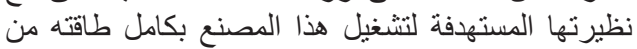

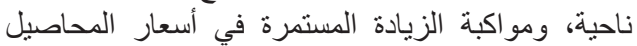
الشتوية المنافسة له من ناحية أخرى. لـادة.

r. ت ترشيد استخدام موارد العمل البشرى والسماد الفوسفاتي و المبيدات في عروات انتاج محصول بنجر السكر الثلاث ، وذللك حتى يتحقى الاستخدام الكفء لتنلك المو ارد .

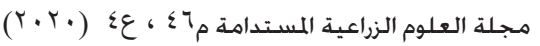




\title{
Competition of The Seedtime of Sugar beet Compared to the Most Important Winter Crops: Case Study in Dakahlia Governorate
}

\author{
Moustafa A. El kblawy ${ }^{1}$ and Hebat Allah Elsyed ${ }^{2}$ \\ ${ }^{1}$ Economic Research Institute, Agricultural Research Center, Gaza, Egypt \\ ${ }^{2}$ Department Agricultural Economic. , Faculty of Agriculture, Mansoura University
}

$\mathbf{T}$

HE RESEARCH aims to study a competitive study of sugar beet lugs for the most important winter crops in Dakahlia Governorate, and set some pricing options for the unit output of these lugs in light of the competitiveness of these crops. The most important results were that the municipal bean crop achieved the highest net return and return of the pound with values of about 5651.4, 0.41 pounds, followed by persistent clover with values of about 4695.9 and 0.36 pounds, and finally wheat with values amounting to 4490.1 and 0.32 pounds, respectively, during the production season 2018 / 2019, and by comparing these results with their counterparts with sugar beet lugs, they were found to be less profitable than those winter crops. By putting substitutes for pricing unit for sugar beet lugs in light of wheat competitiveness, they amounted to $870.6,777.1,731.5$ pounds / ton for the three lugs at rates estimated at $23.6 \%, 16.6 \%, 13.1 \%$ from the current price to equal the net pound return for wheat crops, while for the municipal beans 930 EGP 883.5, EGP 743.3 ton for the three rates, with rates estimated at $32 \%, 32.6 \%$, and $14.9 \%$ of the current price, to equal the net pound return for the municipal beans. While the permanent clover reached 704.5, $666.3,646.9$ pounds / ton for the three lugs, with rates estimated at $27.3 \%, 27.9 \%$, and $10.8 \%$ on the current price to equal the net pound return for the sustainable clover crop, respectively, during the same production season.

Key words: Competition, The Seedtime, Sugar Beet, Winter Crops, Production Costs, Net Return, Pound Return, Economic Efficiency. 